\title{
An Optimal Area Approach to Intercomparing Polarimetric Radar Rain-Rate Algorithms with Gauge Data
}

\author{
S. BOLEN \\ Rome Laboratory, USAF/Rome Laboratory, Rome, New York \\ V. N. BRINGI AND V. CHANDRASEKAR \\ Department of Electrical Engineering, Colorado State University, Fort Collins, Colorado
}

(Manuscript received 28 May 1997, in final form 26 September 1997)

ABSTRACT

\begin{abstract}
An optimal area method is described that is used as a basis for comparing $K_{\mathrm{DP}^{-}},\left(K_{\mathrm{DP}}, Z_{\mathrm{DR}}\right)$, , and $Z_{h}$-based estimates of rain rates with gauge-measured rain rates. The location and dimensions of an elliptically shaped optimal area within the radar scan area surrounding the gauge are determined objectively via an rms error minimization of the difference between the $K_{\mathrm{DP}}$-based radar estimate and gauge data and via use of the spatial structure of the rms difference field itself. Four convective events were analyzed with rain rates in the range of 20-120 $\mathrm{mm} \mathrm{h}^{-1}$, with two of the events containing marble-sized hail. The analysis shows that excellent results could be achieved using $K_{\mathrm{DP}}$-based rain-rate estimators.
\end{abstract}

\section{Introduction}

Polarimetric radar algorithms offer a physically based approach to rain-rate estimation. In particular, algorithms based on specific differential phase $\left(K_{\mathrm{DP}}\right)$, or $K_{\mathrm{DP}}$ combined with differential reflectivity $\left(Z_{\mathrm{DR}}\right)$, are not only relatively insensitive to drop size distribution (DSD) fluctuations but also offer several practical advantages (Chandrasekar et al. 1990; Ryzhkov and Zrnic 1995; Zrnic and Ryzhkov 1996). Only recently have research radars been able to routinely measure the differential propagation phase $\left(\Phi_{\mathrm{DP}}\right.$; Mueller 1984) from which $K_{\mathrm{DP}}$ is estimated. As a consequence, there have been relatively few opportunities for quantitative assessment of $K_{\mathrm{DP}^{-}}$or $\left(K_{\mathrm{DP}}, Z_{\mathrm{DR}}\right)$-based rain-rate algorithms with rain gauges (Aydin et al. 1995; Ryzhkov and Zrnic 1995). However, rain-rate algorithms based on $\left(Z_{h}, Z_{\mathrm{DR}}\right)$ have been quantitatively assessed against disdrometers and gauges; the results are remarkably consistent among the various studies in terms of bias $(5 \%-10 \%)$ and fractional standard errors $(30 \%-40 \%)$ (Goddard and Cherry 1984; Aydin et al. 1987; Aydin et al. 1990; Gorgucci et al. 1995).

Radar-rain gauge comparisons are complicated by various error sources, for example, space-time smoothing of radar-gauge data, horizontal drift of

Corresponding author address: Dr. V. N. Bringi, Department of Electrical Engineering, Colorado State University, Fort Collins, CO 80523.

E-mail: bringi@engr.colostate.edu raindrops, changes in DSD with height, etc. (Zawadzki 1975, 1984). It is conventional to choose a square $L \times L$ measurement cell, centered on the gauge, over which the radar data are spatially averaged; it is also conventional to average the gauge rain rate over a time interval $\Delta t$. Zawadzki (1975) suggested a procedure for an optimum smoothing of radar and gauge data based on storm speed/direction and decorrelation distance/time of the rain-rate field. A comprehensive comparison of rainfall amounts from radar (via $Z-R$ relations) and rain gauges was made by Austin (1987). This study emphasized the effects of various physical factors such as, for example, size distribution variations, hail bias, etc., on radar rain rates, and methods of compensation were proposed using different $Z-R$ relations or limiting the maximum rain rate by truncating $Z$. Using radar-derived mean cell speed and direction, Austin (1987) used an advection procedure to obtain continuous time sequences of $Z$ over the gauge location. Aydin et al. (1987) used a method of locating an optimal area over which the radar $Z_{h}$ and $Z_{\mathrm{DR}}$ were averaged before comparing to the disdrometer. Their method was based on choosing those subareas or swaths within the radar PPI scan that maximized the (time delayed) cross correlation between radar $Z_{h}$ and disdrometer-calculated $Z_{h}$. Their hypothesis was that such swaths would determine an optimal region that most likely contributed to the disdrometer measurements and, thus, be used as a basis for comparing $R\left(Z_{h}, Z_{\mathrm{DR}}\right)$ and $R\left(Z_{h}\right)$ against disdrometer-calculated $R$. 
TABLE 1. System characteristics of the CSU-CHILL radar.

\begin{tabular}{|c|c|}
\hline \multicolumn{2}{|l|}{ Antenna } \\
\hline Type & Fully steerable, prime focus parabolic reflector \\
\hline Size & $8.5 \mathrm{~m}$ in diameter \\
\hline Feed & Scalar horn \\
\hline 3-dB beamwidth & $1.0^{\circ}$ \\
\hline Directivity & $45 \mathrm{~dB}$ \\
\hline Sidelobe level (any $\phi$ plane) & $\leq-27 \mathrm{~dB}$ \\
\hline Cross-polarization level (any $\phi$ plane) & $\leq-30 \mathrm{~dB}$ \\
\hline Polarization radiated & Horizontal or vertical \\
\hline \multicolumn{2}{|l|}{ Transmitter } \\
\hline Type & Klystron, modernized FPS-18 \\
\hline Wavelength & $10.7 \mathrm{~cm}$ \\
\hline Peak power & $700-1000 \mathrm{~kW}$ \\
\hline Pulse width & Steps of $0.1 \mu \mathrm{s}$ up to a maximum of $1.0 \mu \mathrm{s}$ \\
\hline PRT & $800-2500 \mu \mathrm{s}$ \\
\hline Maximum unambiguous range & $375 \mathrm{~km}$ \\
\hline Maximum unambiguous velocity & $\pm 34.3 \mathrm{~m} \mathrm{~s}^{-1}$ \\
\hline \multicolumn{2}{|l|}{ Receiver } \\
\hline Noise figure & $0.7 \mathrm{~dB}$ \\
\hline Noise power & $-114 \mathrm{dBm}$ \\
\hline Typical bandwidth & $750 \mathrm{kHz}$ \\
\hline Transfer function & Linear \\
\hline Dynamic range & $90 \mathrm{~dB}, 0-60 \mathrm{~dB}$ IAGC in $12-\mathrm{dB}$ steps \\
\hline \multicolumn{2}{|l|}{ Variables available } \\
\hline \multicolumn{2}{|l|}{ Reflectivity at horizontal polarization $\left(Z_{h}\right)$} \\
\hline \multicolumn{2}{|l|}{ Differential reflectivity $\left(Z_{\mathrm{DR}}\right)$} \\
\hline \multicolumn{2}{|c|}{ Mean Doppler velocity $(\bar{v})$ and spectral width $\left(\sigma_{v}\right)$} \\
\hline \multicolumn{2}{|c|}{ Differential phase between horizontal and vertical states $\left(\psi_{\mathrm{DP}}\right)$} \\
\hline \multicolumn{2}{|l|}{ Copolar correlation coefficient $\left[\rho_{\text {hv }}(0)\right]$} \\
\hline \multicolumn{2}{|l|}{ Linear depolarization ratio (LDR) } \\
\hline \multicolumn{2}{|l|}{ Doppler spectra from FFT processing } \\
\hline$I, Q$, and $\log (P)$ for every pulse in tim & \\
\hline
\end{tabular}

In this paper, an approach similar in principle to Aydin et al. (1987) is adapted using $K_{\mathrm{DP}}$ measurements with the CSU-CHILL radar. An objective procedure for locating an elliptically shaped optimal area is described that minimizes the rms error difference between $R\left(K_{\mathrm{DP}}\right)$ and gauge rain rate over an appropriate time interval. The dimensions of the ellipse are obtained from the spatial correlation structure of the rms error field. This approach sets the basis for evaluating different radar rain algorithms against gauge data. This type of methodology is based on the assumption that the $R\left(K_{\mathrm{DP}}\right)$ rain-rate estimator is essentially unbiased, as supported by past experimental evidence as well as through simulations (Ryzhkov and Zrnic 1995; Aydin et al. 1995; Chandrasekar et al. 1990). Our objective here is to quantitatively assess the performance of $R\left(K_{\mathrm{DP}}\right)$, $R\left(K_{\mathrm{DP}}, Z_{\mathrm{DR}}\right)$, and $Z-R$ algorithms for comparison against theoretical predictions.

This paper begins with a brief description of data sources, followed by an overview of the CSU-CHILL radar measurements of four events: two of which occurred on 20 June 1994, one event occurred on 2 June 1995, and the final event was on 6 July 1996. A detailed description of the optimal area method is given next using the 2 June 1995 case as an example. Results from the four cases are then discussed and placed in context with past studies.

\section{Data sources}

\section{a. CSU-CHILL radar}

During the summer of 1994 (and prior to this), the CSU-CHILL radar was configured as a conventional single transmitter/single receiver system with a highpower polarization switch permitting measurement of $Z_{h}, Z_{\mathrm{DR}}$, and $\Phi_{\mathrm{DP}}$. In January 1994 a new dual-polarized antenna with superior sidelobe levels (worst-case sidelobe of $-27 \mathrm{~dB}$ ) and excellent cross-polar characteristics was installed for a future modification to the system that would permit measurement of the complete polarimetric covariance matrix. This system upgrade to a two transmitters/two receivers configuration was completed in spring 1995. Table 1 summarizes the system characteristics of the CSU-CHILL radar configuration after the recent upgrades.

Radar data such as $Z_{h}, Z_{\mathrm{DR}}$, and $\Phi_{\mathrm{DP}}$ were available at resolution volumes spaced $150 \mathrm{~m}$ apart with a dwell time of $128 \mathrm{~ms}$ (64 horizontal/vertical polarized pulse pairs). Processing algorithms and measurement errors are given in Doviak and Zrnic (1993). Here, $K_{\mathrm{DP}}$ was derived by postprocessing the raw $\Phi_{\mathrm{DP}}$ range profiles using an adaptive digital range filtering algorithm described by Hubbert and Bringi (1995). The resulting $K_{\mathrm{DP}}$ accuracy is estimated to be within $\pm 0.5^{\circ} \mathrm{km}^{-1}$. 
(a)

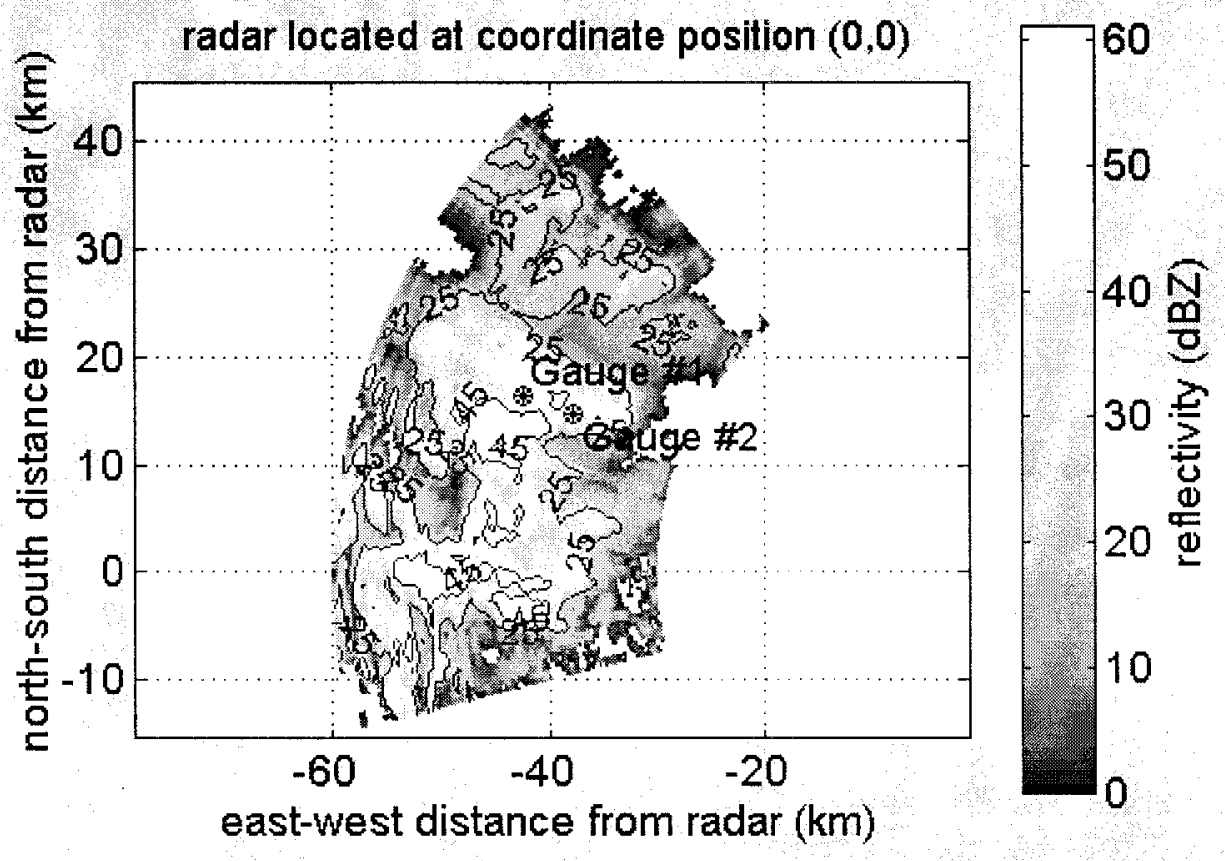

(b)

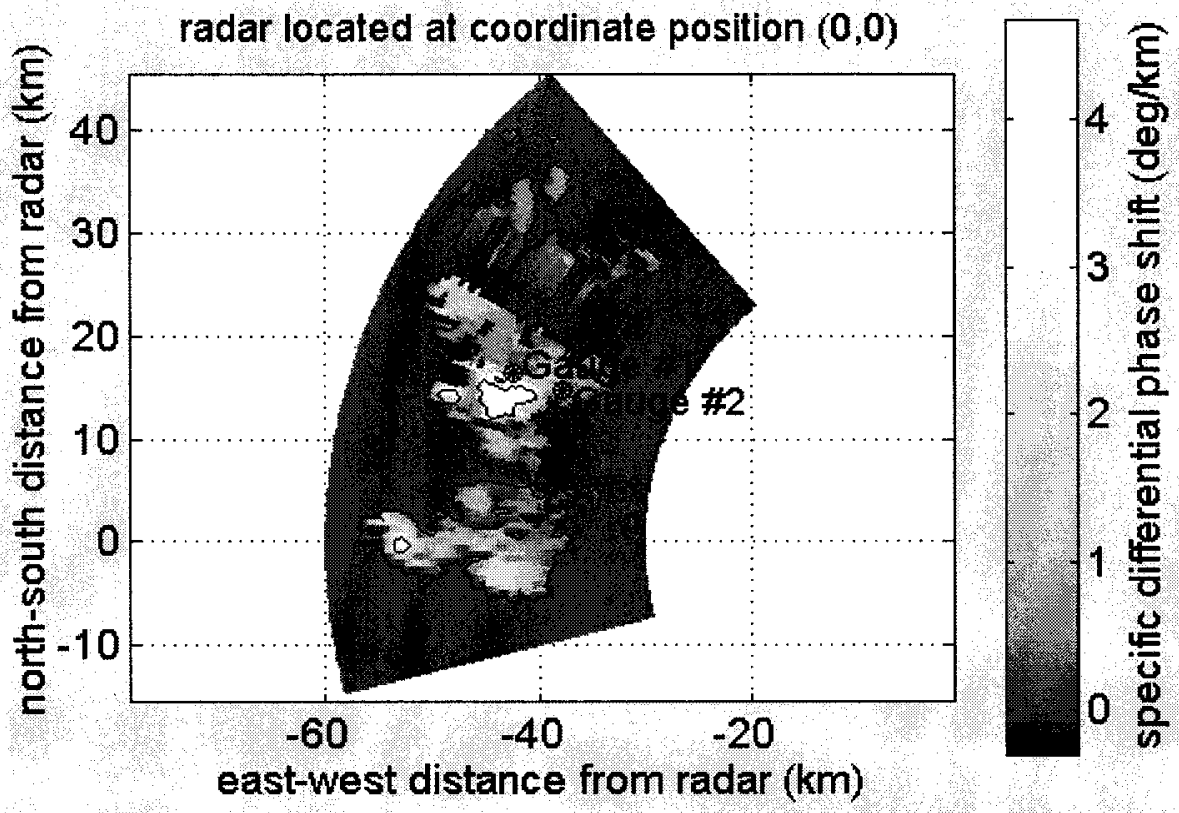

FIG. 1. (a) Contours of $Z_{h}$ for 20 June 1994 event at 1437:21 MDT. PPI scan at elevation angle $0.52^{\circ}$. Locations of gauges 1 and 2 are marked. (b) As in (a) except contours of $K_{\mathrm{DP}}$ are shown. 
(a)

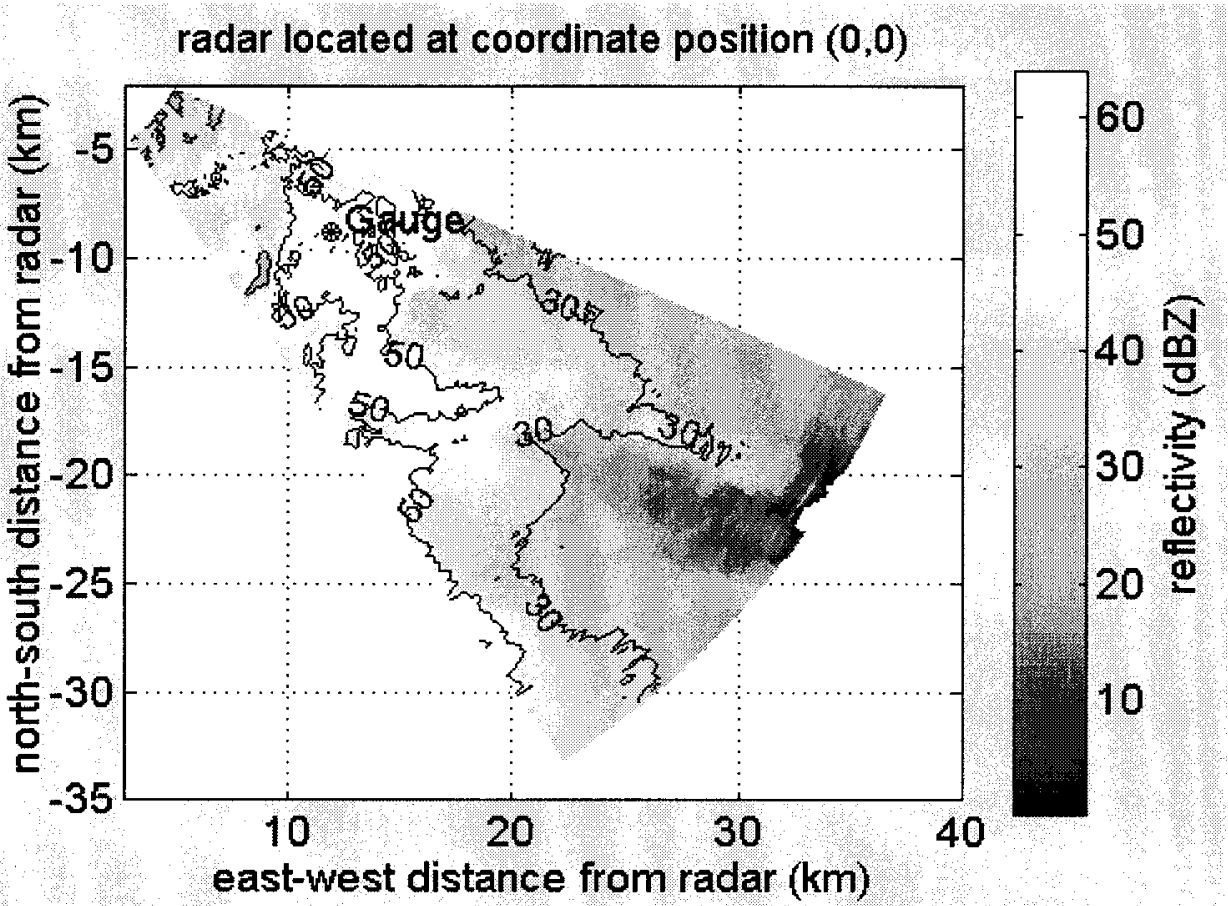

(b)

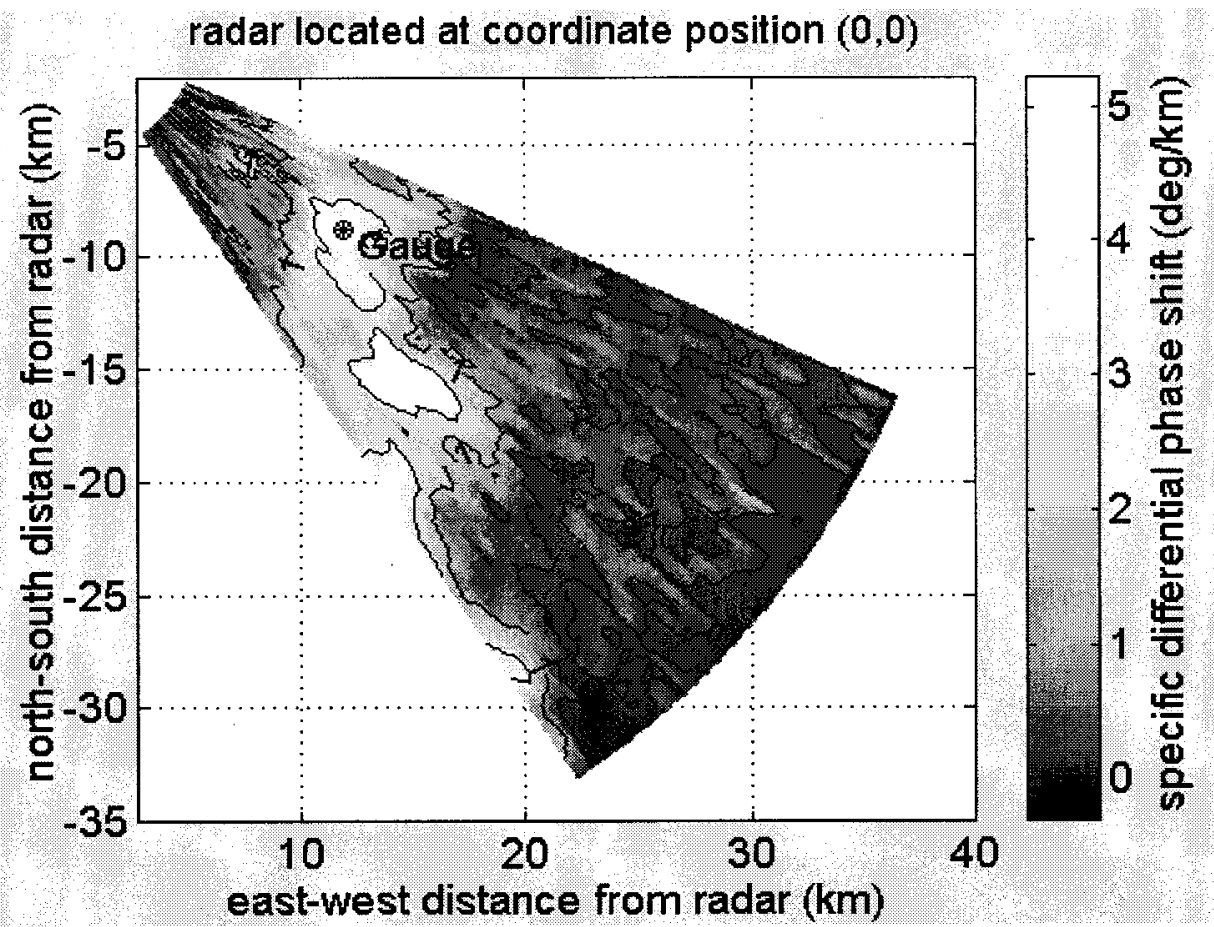

FIG. 2. (a) Contours of $Z_{h}$ for 2 June 1995 event at 1812:14 MDT. PPI scan at elevation angle $0.98^{\circ}$. (b) As in (a) except contours of $K_{\mathrm{DP}}$ are shown 
(a)

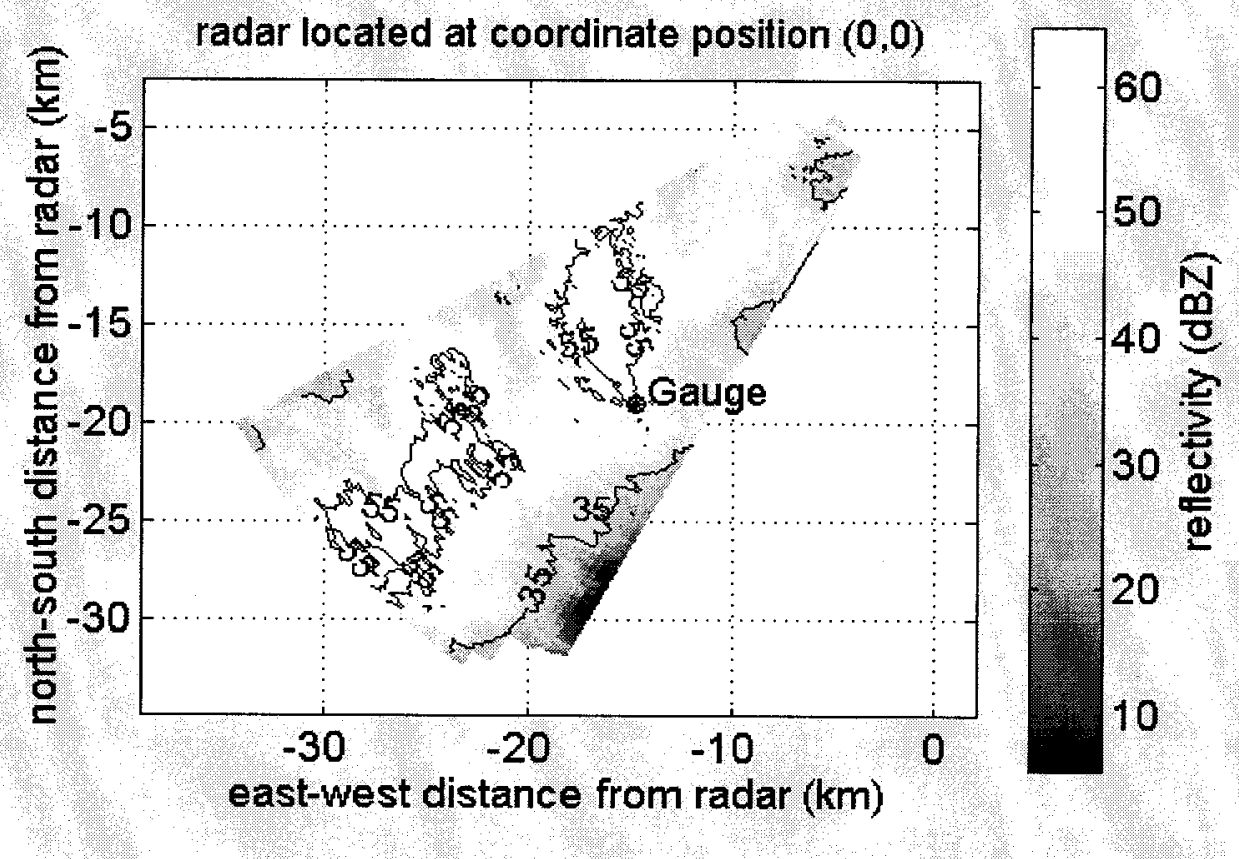

(b)

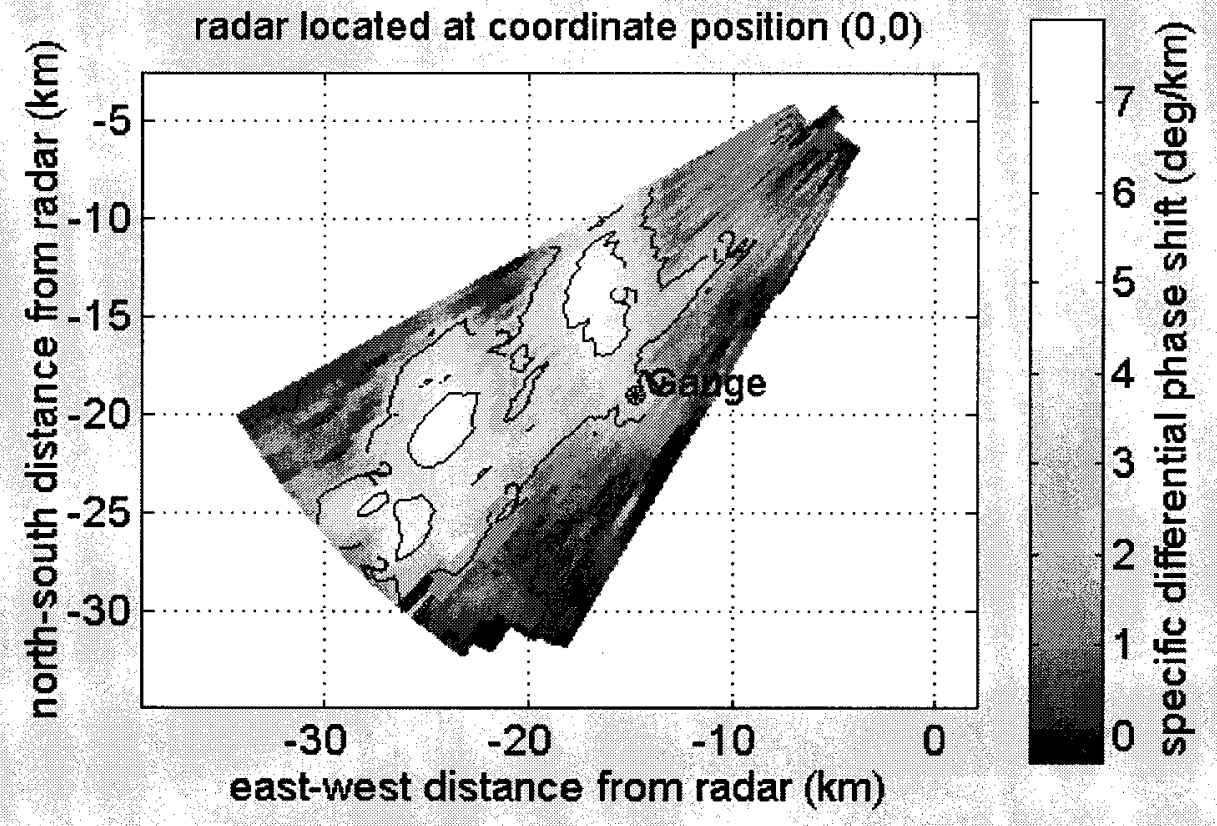

FIG. 3. (a) Contours of $Z_{h}$ for 6 July 1996 event at 1931:00 MDT. PPI scan at elevation angle $1.1^{\circ}$. (b) As in (a) except contours of $K_{\mathrm{DP}}$ are shown. 
TABLE 2. Radar algorithms of rain rate $\left(\mathrm{mm} \mathrm{h}^{-1}\right)$ and references. Note: $K_{\mathrm{DP}}$ in deg $\mathrm{km}^{-1}, Z_{\mathrm{DR}}$ in $\mathrm{dB}$, and $Z_{h}$ in units of $\mathrm{mm}^{6} \mathrm{~m}^{-3} . Z_{h}, 55$ means truncated at $55(53,51 \mathrm{dBZ})$, respectively.

\begin{tabular}{rlrl}
\hline \hline$R\left(K_{\mathrm{DP}}\right)$ & $=40.5\left(K_{\mathrm{DP}}\right)^{0.85}$ & & Chandrasekar et al. $(1990)$ \\
$R\left(K_{\mathrm{DP}}, Z_{\mathrm{DR}}, 1\right)$ & $\left.=52.0\left[\left(K_{\mathrm{DP}}\right)^{0.96}\right]\left[Z_{\mathrm{DR}}\right)^{-0.447}\right]$ & & Ryzhkov and Zrnic (1995) \\
$R\left(K_{\mathrm{DP}}, Z_{\mathrm{DR}}, 2\right)$ & $=67.152\left[\left(K_{\mathrm{DP}}\right)^{0.956}\right](10)^{-0.125\left(Z_{\mathrm{DR}}\right)}$ & & Derived from Gorgucci et al. (1994) \\
$R\left(Z_{h}\right)$ & $=0.017\left(Z_{h}\right)^{0.714}$ & & Kelsh (1989) \\
$R\left(Z_{h}, 55\right)$ & $=0.017\left(Z_{h}, 55\right)^{0.714}$ & & - \\
$R\left(Z_{h}, 53\right)$ & $=0.017\left(Z_{h}, 53\right)^{0.714}$ & & - \\
$R\left(Z_{h}, 51\right)$ & $=0.017\left(Z_{h}, 51\right)^{0.714}$ & & - \\
\hline
\end{tabular}

\section{b. Rain gauges}

For the first event on 20 June 1994, a tipping-bucket gauge (gauge 1 in Fig. 1) at Christman Field (located about $1 \mathrm{~km}$ southeast of the Atmospheric Sciences Department at Colorado State University) was used. This gauge recorded rainfall accumulations every 5 min over the event duration of around $40 \mathrm{~min}$. The distance of the gauge to the CSU-CHILL radar is $45.5 \mathrm{~km}$. For the second event on 20 June 1994, a weighing-bucket gauge (gauge 2 in Fig. 1) with analog strip chart recorder located at the campus weather station was used. Rain rate was estimated from the graphical recording. The distance of the gauge from the CSU-CHILL radar is $40.7 \mathrm{~km}$.

For the 2 June 1995 and 6 July 1996 events, a Young capacitance rain gauge (interfaced to a PC) was installed in a mobile chase van that was directed from the radar for storm intercept. The PC recorded rainfall accumulation every few seconds. The distance of the gauge to the radar in these events was around $15 \mathrm{~km}$ for the 2 June 1995 and $24 \mathrm{~km}$ for the 6 July 1996 event. A comparison of the performance characteristics of the tipping-bucket and Young gauges can be found in Nystuen et al. (1996). For rain rate greater than $5 \mathrm{~mm} \mathrm{~h}^{-1}$, the mean relative error (for 1-min rain rate) for the capacitance gauge was estimated at $14 \%$; for rain rate greater than $50 \mathrm{~mm} \mathrm{~h}^{-1}$, the error drops down to $12 \%$. Similar errors for the tipping-bucket gauge were not reported since the rain-rate precision for a 1 -min interval is $\pm 12 \mathrm{~mm} \mathrm{~h}^{-1}$ (based on one tip per minute).

\section{Brief overview of storm events}

a. 20 June 1994

An intense storm developed on this day over the foothills west of Fort Collins, Colorado, which was ob-
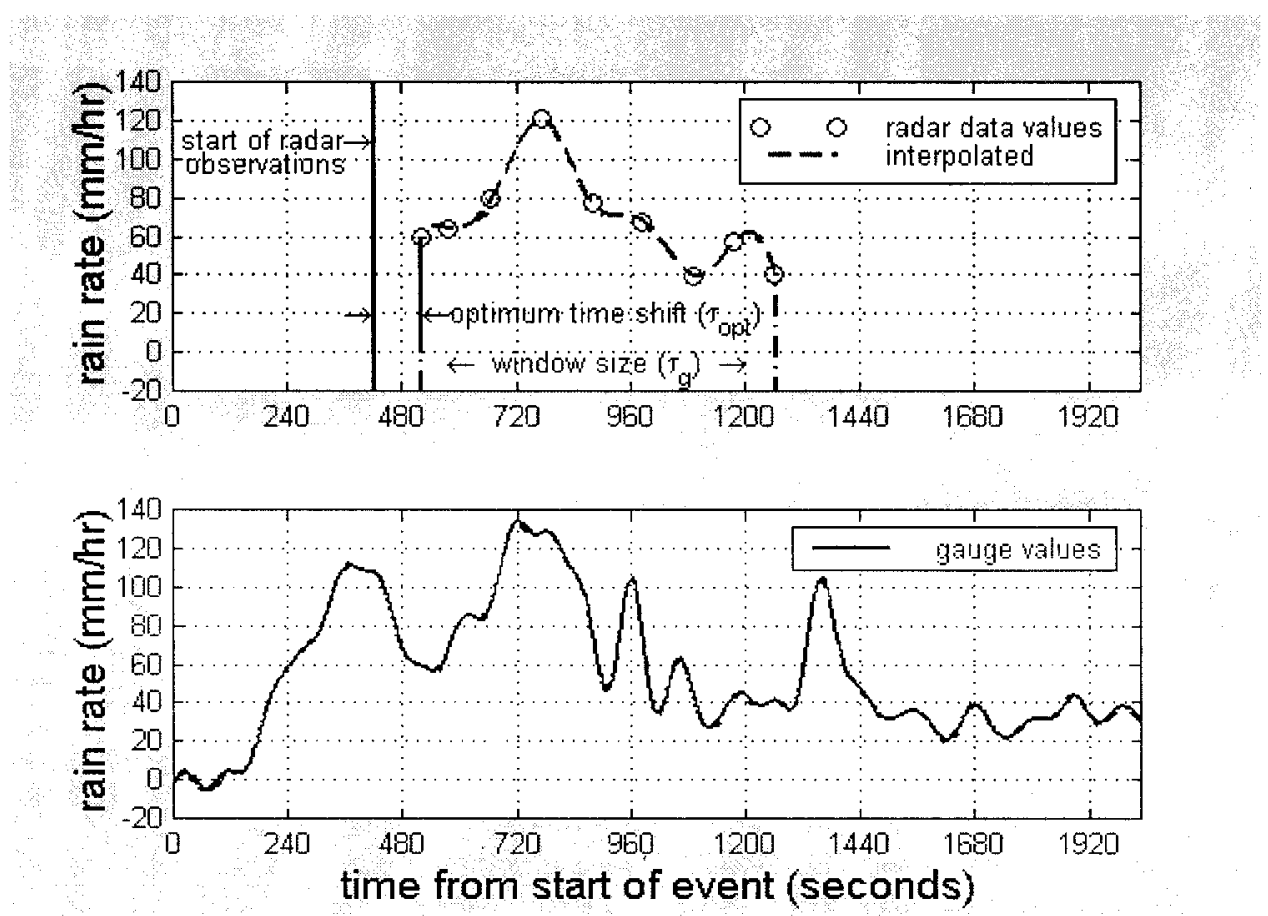

FIG. 4. (a) Top panel shows the radar rain-rate estimate $R\left(K_{\mathrm{DP}}\right)$ from Table 2 for the 2 June 1995 event. (b) Bottom panel shows the gauge rain rate. The optimum time shift $\left(\tau_{\text {opt }}\right)$ is shown in the top panel. 
(a)

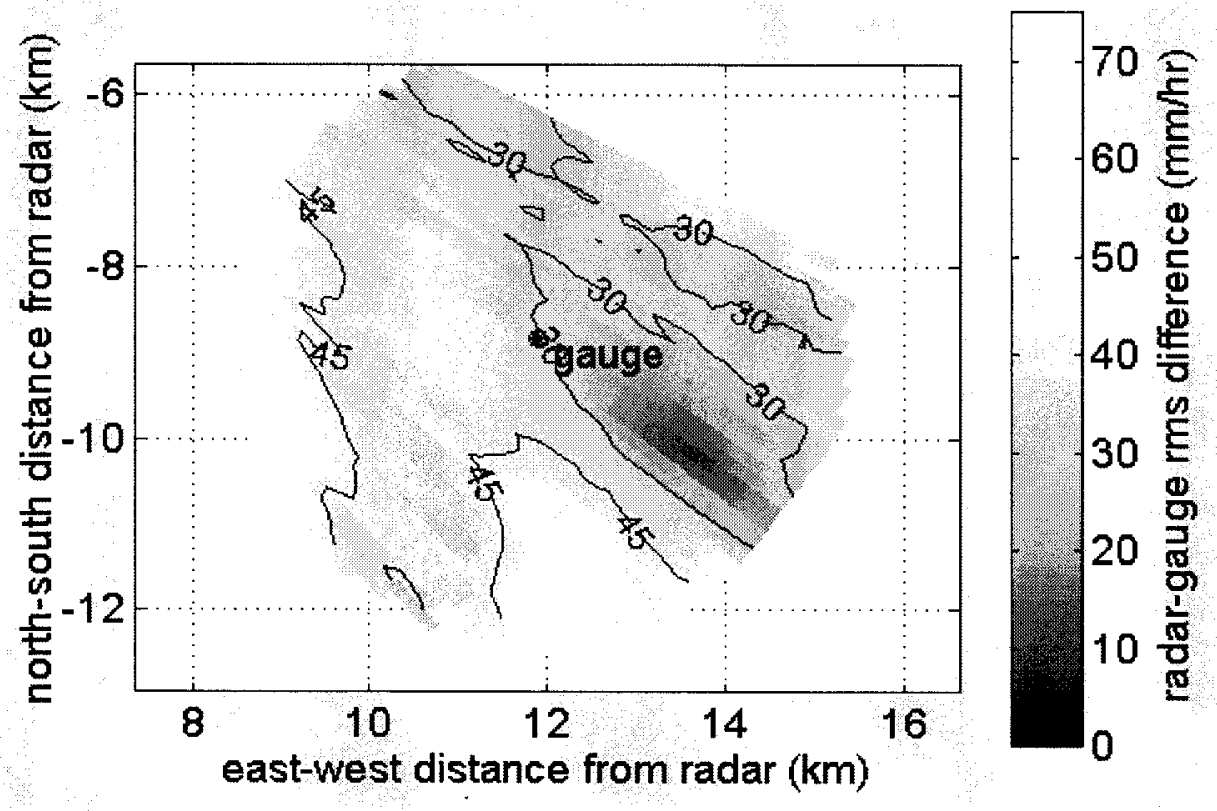

(b)

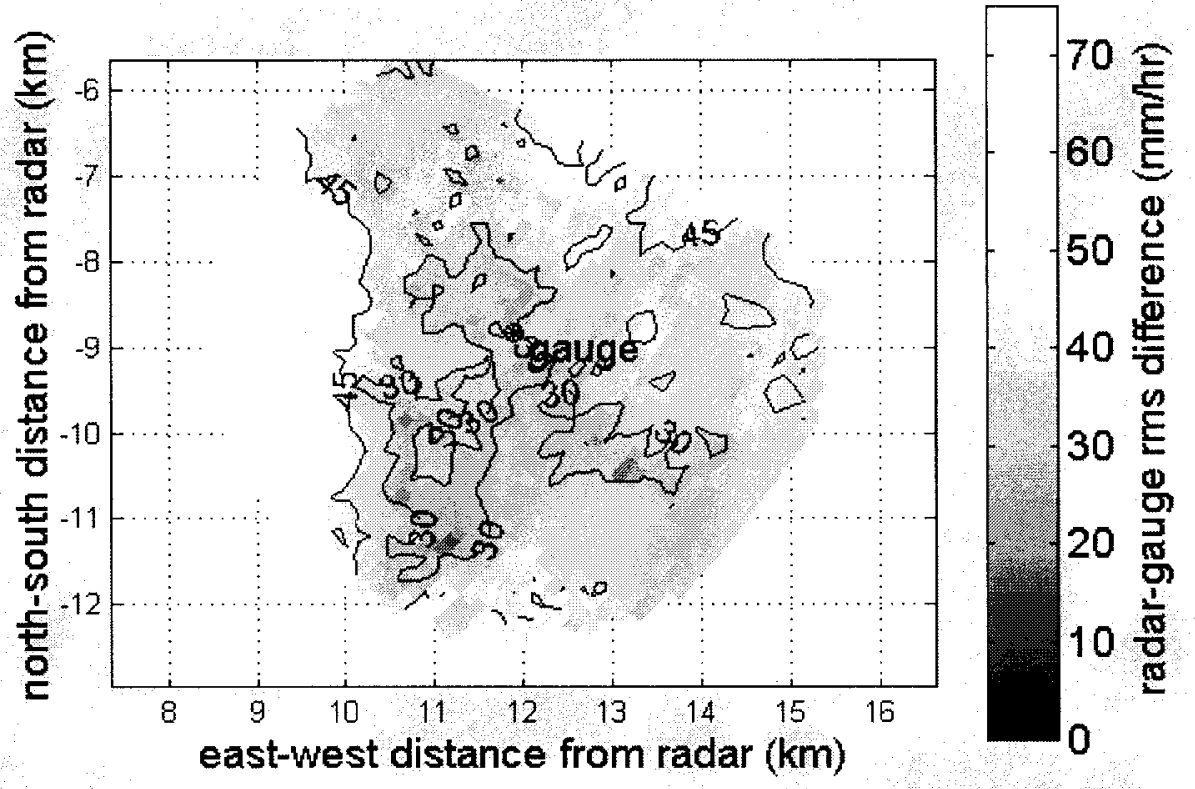

FIG. 5. (a) Contours of radar-gauge rms difference $\left(\mathrm{mm} \mathrm{h}^{-1}\right)$ with $\tau$ set to $\tau_{\text {opt }}$. The $R\left(K_{\mathrm{DP}}\right)$ algorithm in Table 2 is used. Data are from the 2 June 1995 event. (b) As in (a) except $R\left(Z_{h}, 53\right)$ algorithm from Table 2 is used. 
(a)

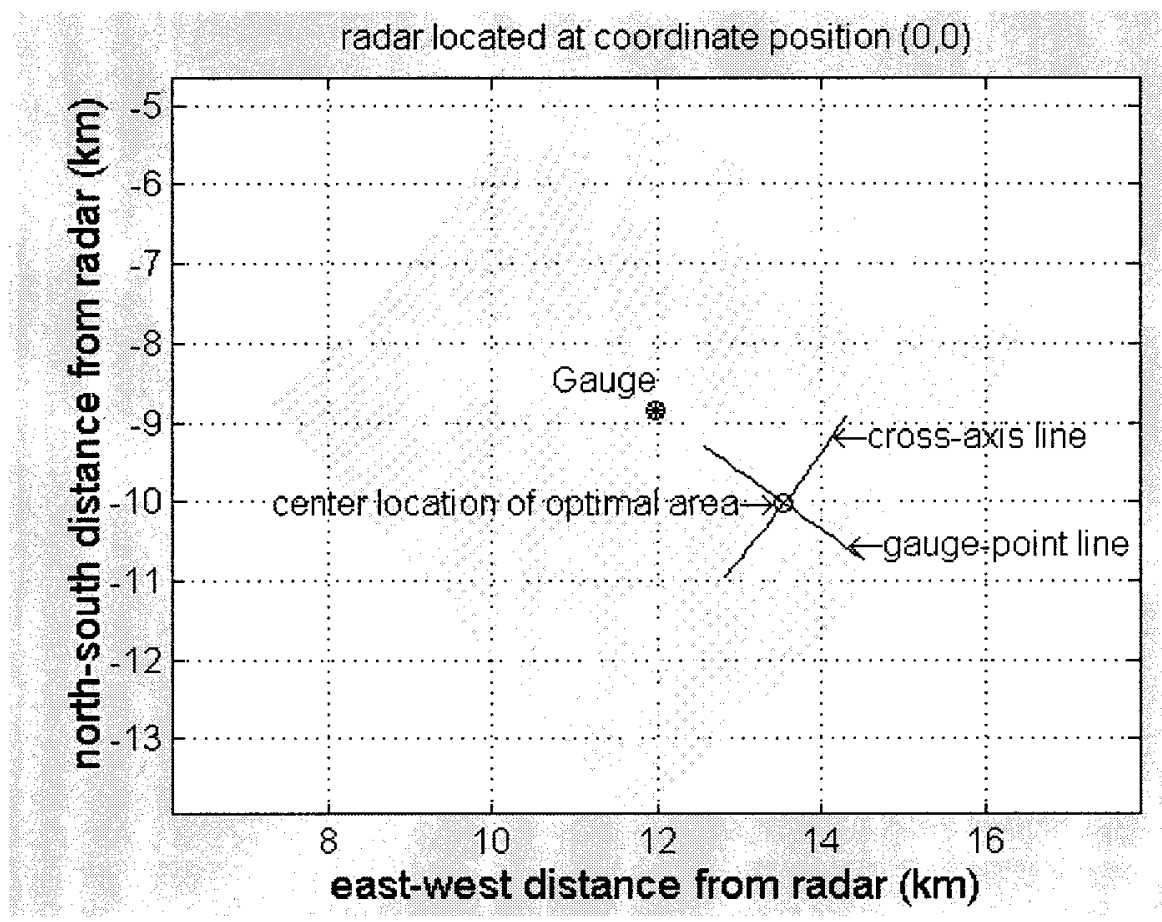

(b)
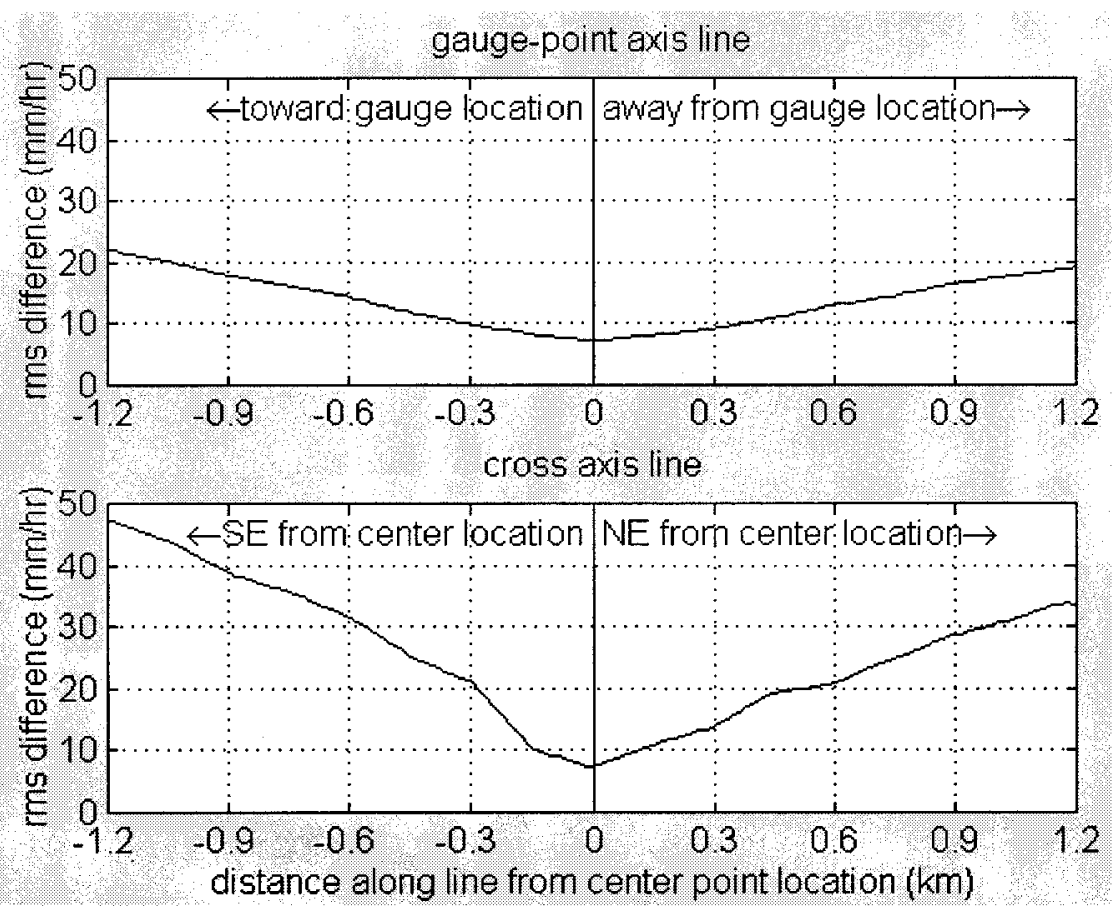

FIG. 6. (a) Location of the optimal area with respect to the gauge. The gauge-point axis line is shown together with the cross-axis line. Data are from the 2 June 1995 event. (b) Top panel shows the rms difference values $\left(\mathrm{mm} \mathrm{h}^{-1}\right)$ along the gauge-point axis line. Bottom panel shows the values along the cross-axis line (with compass directions as indicated). (c) Top panel shows autocorrelation of the rms difference with decorrelation distance along the gauge-point axis line. Bottom panel as in the top panel except along the crossaxis line. 
(c)
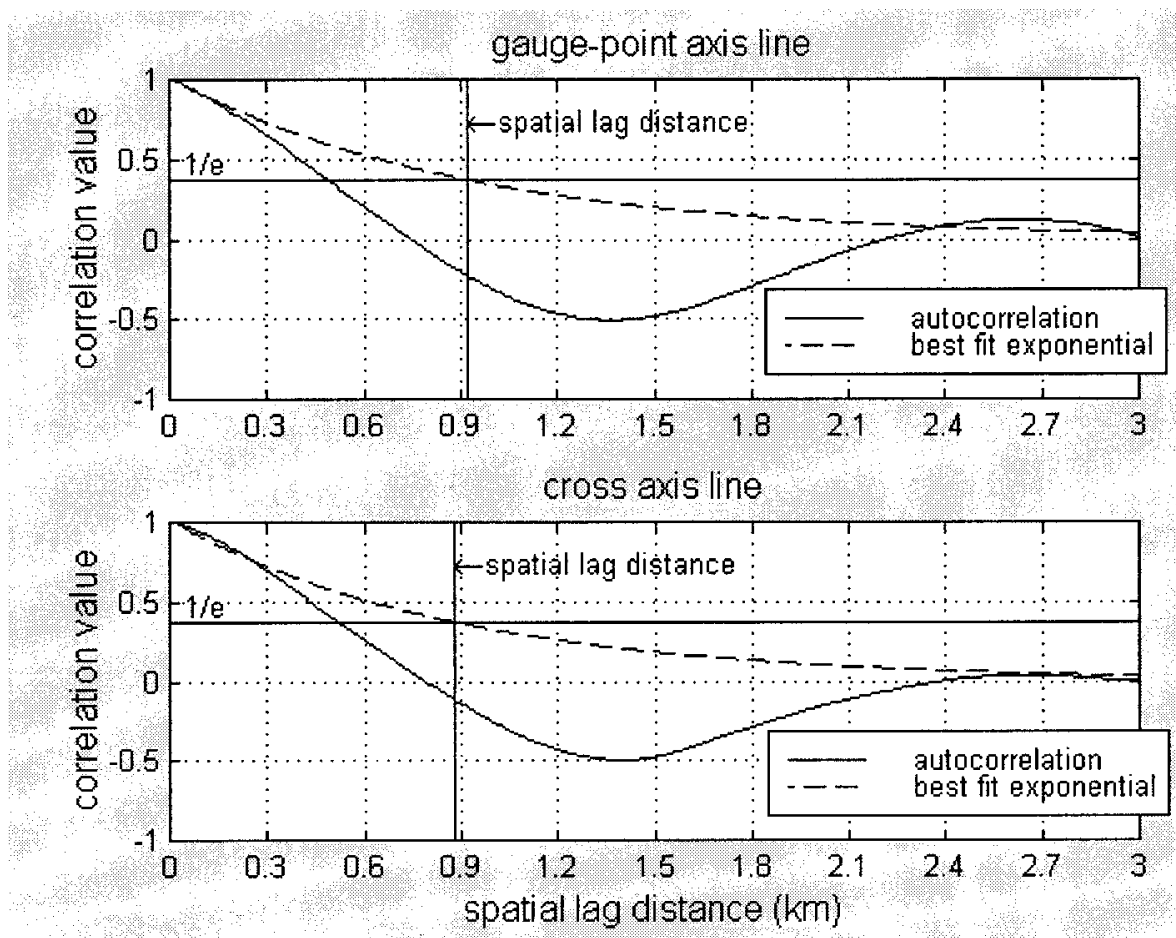

FIG. 6. (Continued)

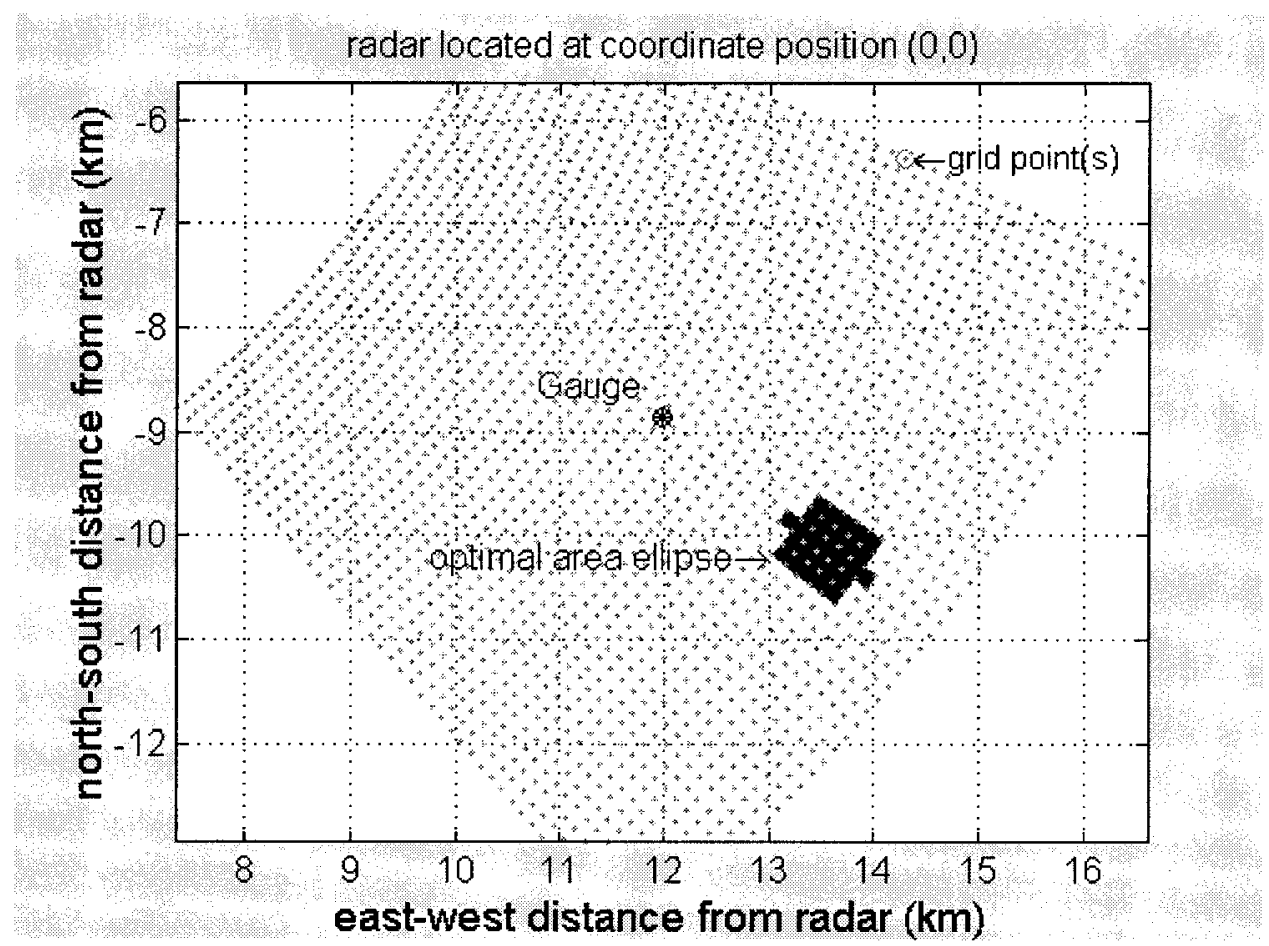

FIG. 7. Size and location of the optimal area with respect to the gauge for the 2 June 1995 event. Error minimization done using the $R\left(K_{\mathrm{DP}}\right)$ algorithm from Table 2 . 
(a)
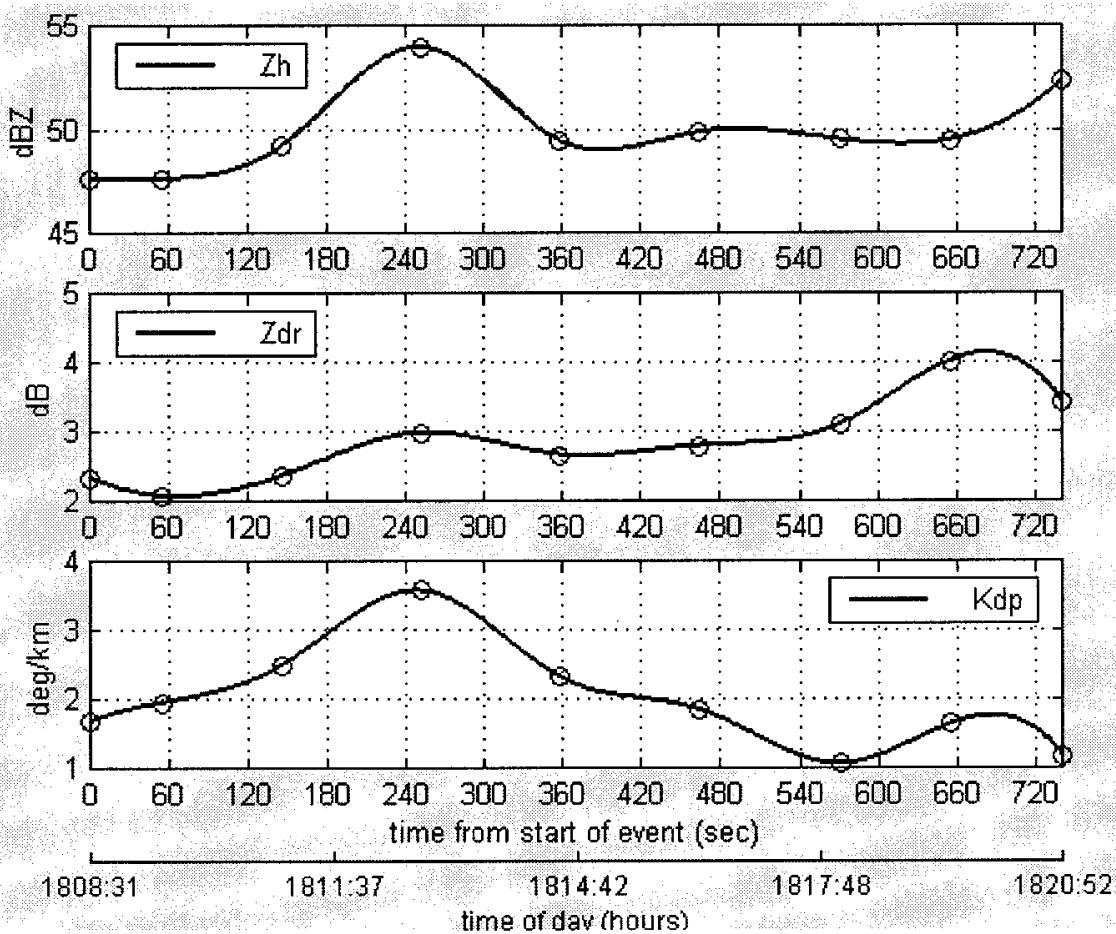

(b)

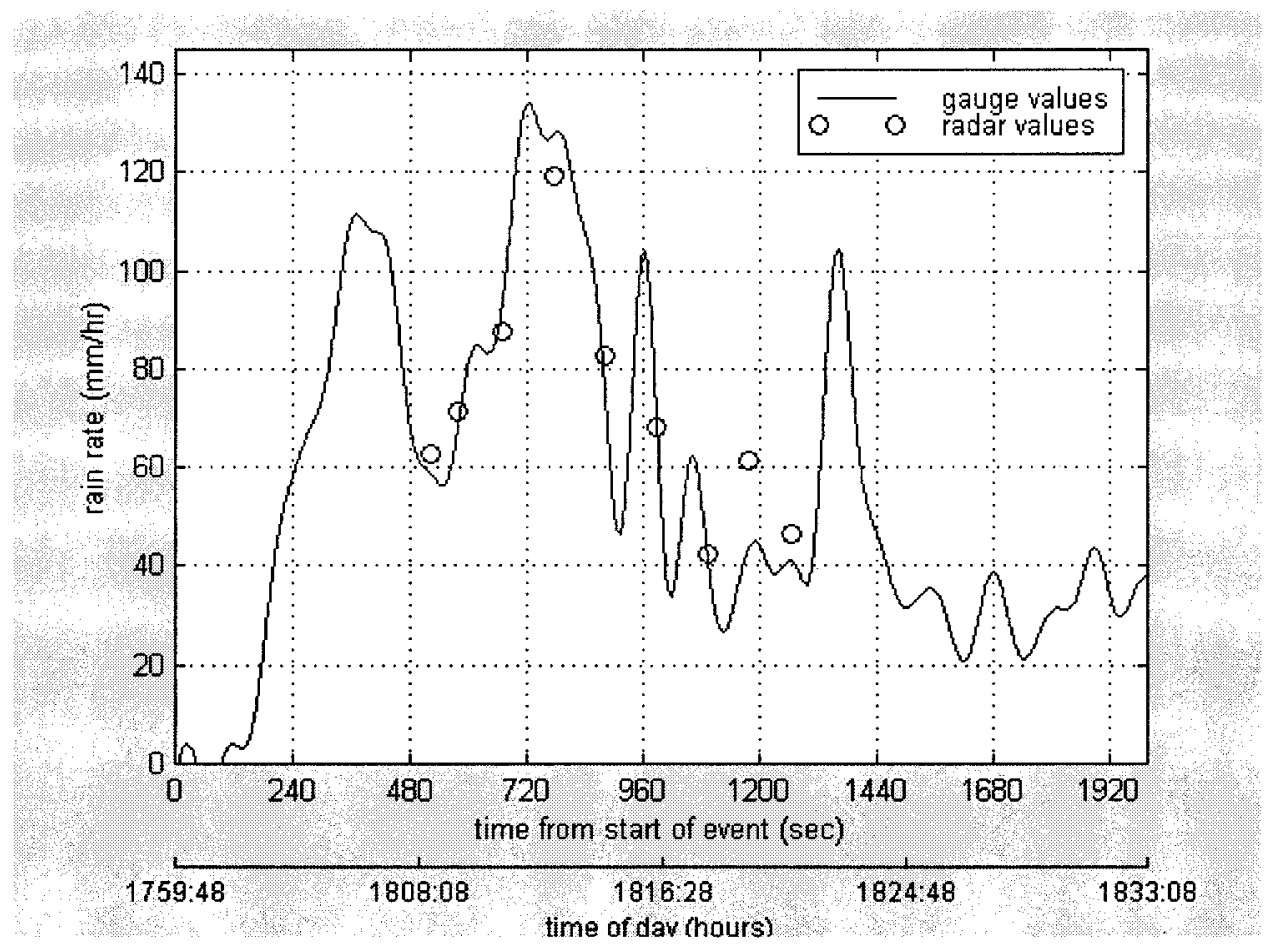

FIG. 8. (a) Time series of $Z_{h}$ (top panel), $Z_{\mathrm{DR}}$ (middle panel), and $K_{\mathrm{DP}}$ (bottom panel) after averaging over the optimal area. Open circles show the data points. Event is 2 June 1995. (b) Radar rain rate from $R\left(K_{\mathrm{DP}}\right)$ in Table 2 shown as open circles compared against the rain gauge (solid line). (c) Cumulative rainfall amounts from $R\left(K_{\mathrm{DP}}\right), R\left(K_{\mathrm{DP}}, Z_{\mathrm{DR}}, 1\right)$, and $R\left(Z_{h}, 53\right)$ compared with the gauge amounts over time. 
(c)

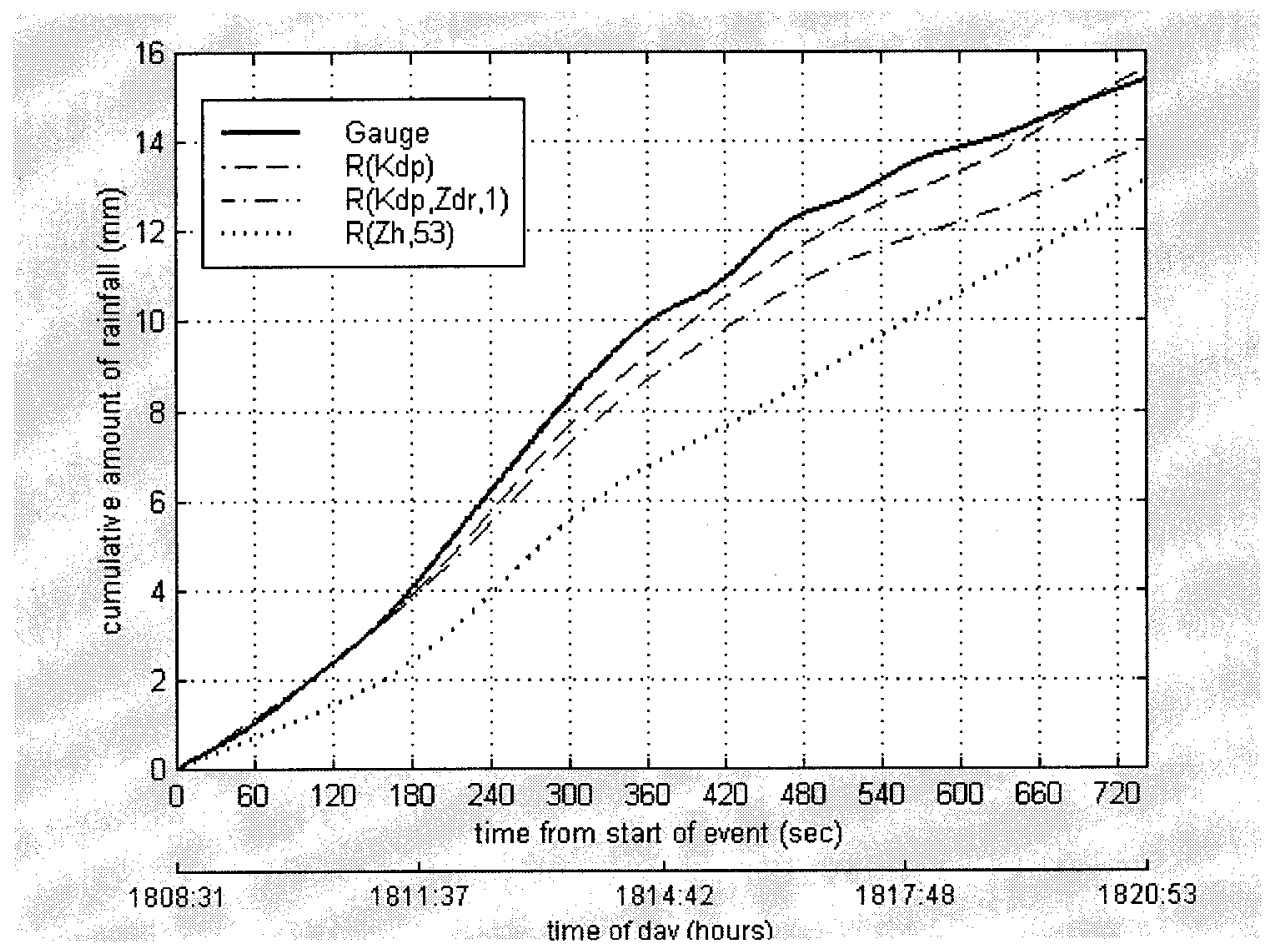

FIG. 8. (Continued)

served by the CSU-CHILL radar for several hours. This storm dumped $2-3$ in. (50-75 mm) of rain, causing urban flooding in Fort Collins. Observers at the Department of Atmospheric Science reported heavy rain mixed at times with marble-sized hail. This event is referred to as the first event (gauge 1 in Fig. 1) for this storm. The storm complex subsequently moved southeast over the campus area, which is referred to as the second event (gauge 2 in Fig. 1). No hail was reported during the campus event.

Figure 1 shows contours of (a) $Z_{h}$ and (b) $K_{\text {DP }}$ at an elevation angle of $0.5^{\circ}$, that is, PPI scan data, during the central time of the first event (1437 MDT).
Radar PPI data is laid onto a Cartesian plane with the radar fixed at coordinate position $(0,0)$. Axis units are in kilometers from the radar position; $x$ axis is east-west and $y$ axis is north-south distance. The locations of the two are gauges are shown in both panels. In (a) the sidebar gives the grayscale intensity of $Z_{h}(\mathrm{dBZ})$ and in (b) $K_{\mathrm{DP}}\left(\operatorname{deg~} \mathrm{km}^{-1}\right)$. PPI scans at this elevation angle were available at intervals of approximately $9 \mathrm{~min}$, compared to the tipping-bucket recording interval of rainfall accumulation every $5 \mathrm{~min}$. Figure 1 shows the cellular structure of $Z_{h}$ with a small region of enhanced $K_{\mathrm{DP}}$, (up to $3.5^{\circ} \mathrm{km}^{-1}$ ) just south of gauge 1 .

TABLE 3. Characteristics and physical dimensions of the optimal areas.

\begin{tabular}{lcccc}
\hline \hline \multicolumn{1}{c}{ Property } & $\begin{array}{c}\text { 20 June 1994 } \\
\text { (Gauge 1) }\end{array}$ & $\begin{array}{c}\text { 20 June 1994 } \\
\text { (Gauge 2) }\end{array}$ & 2 June 1995 & 6 July 1996 \\
\hline$\Delta X$ distance from gauge (km) & -2.351 & -1.287 & +1.369 & -0.979 \\
$\Delta Y$ distance from gauge (km) & +1.115 & +1.698 & -1.181 & 0.215 \\
Distance from gauge (km) & 2.602 & 2.131 & 2.021 & 1.003 \\
Ellipse dimensions & & & \\
Gauge-point axis length (km) & 0.960 & 1.070 & 0.920 & 1.020 \\
Cross-axis length (km) & 1.020 & 0.890 & 0.880 & 0.800 \\
Equivalent circular diameter (km) & 0.990 & 0.976 & 0.900 & 0.903 \\
Axis ratio (minor/major) & 0.94 & 0.83 & 0.96 & 0.78 \\
Orientation angle from radar bearing [abs(deg)] & 3.7 & 30.9 & 0.8 & 64.2 \\
Height of radar observations above gauge (km) & 0.413 & 0.369 & 0.255 & 0.240 \\
Beamwidth at gauge location (km) & 0.795 & 0.709 & 0.259 & 0.421 \\
Optimum time shift, $\tau_{\text {opt }}(\mathrm{s})$ & 193 & 139 & 103 & 93 \\
\hline
\end{tabular}


(a)

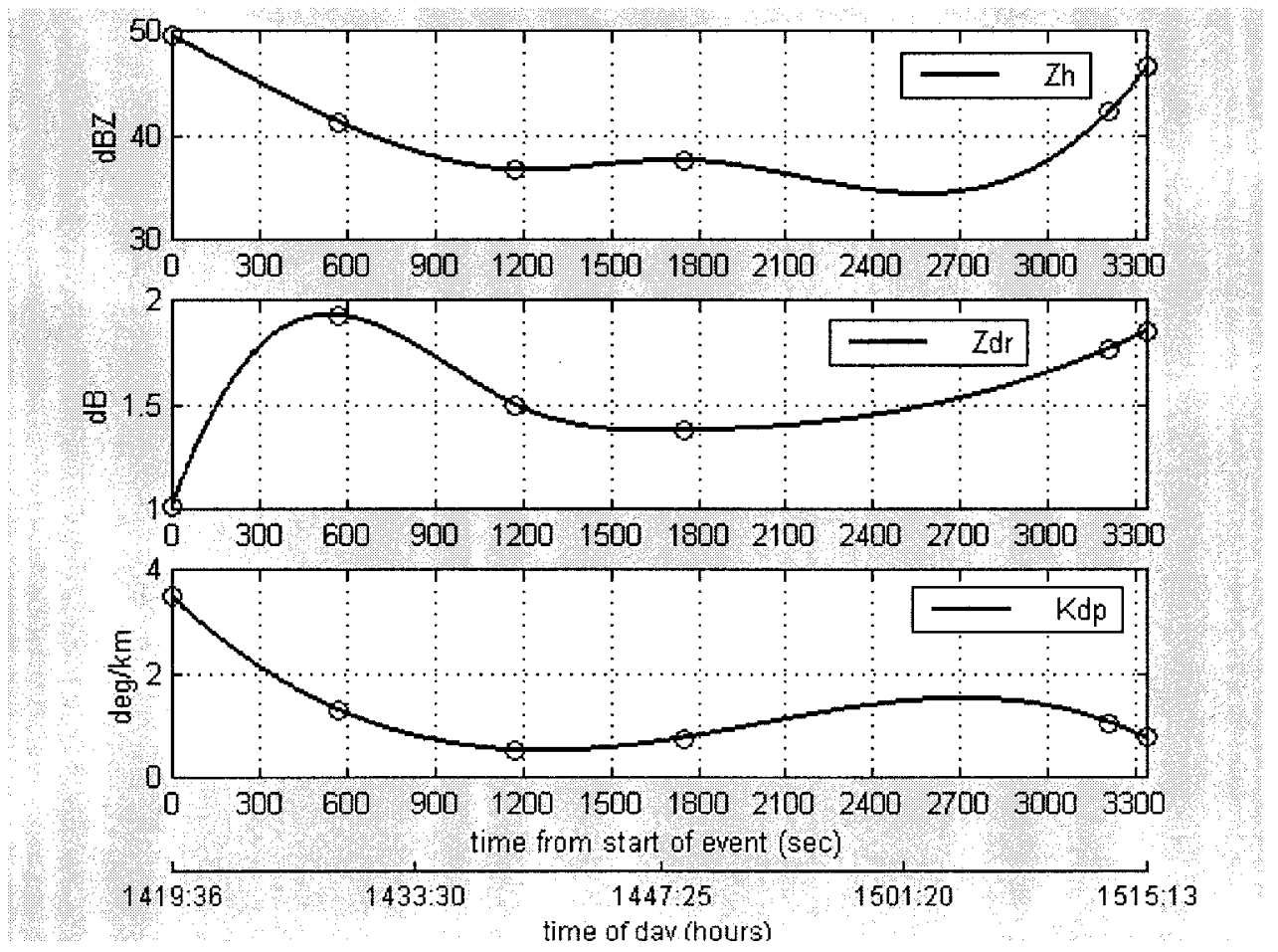

(b)

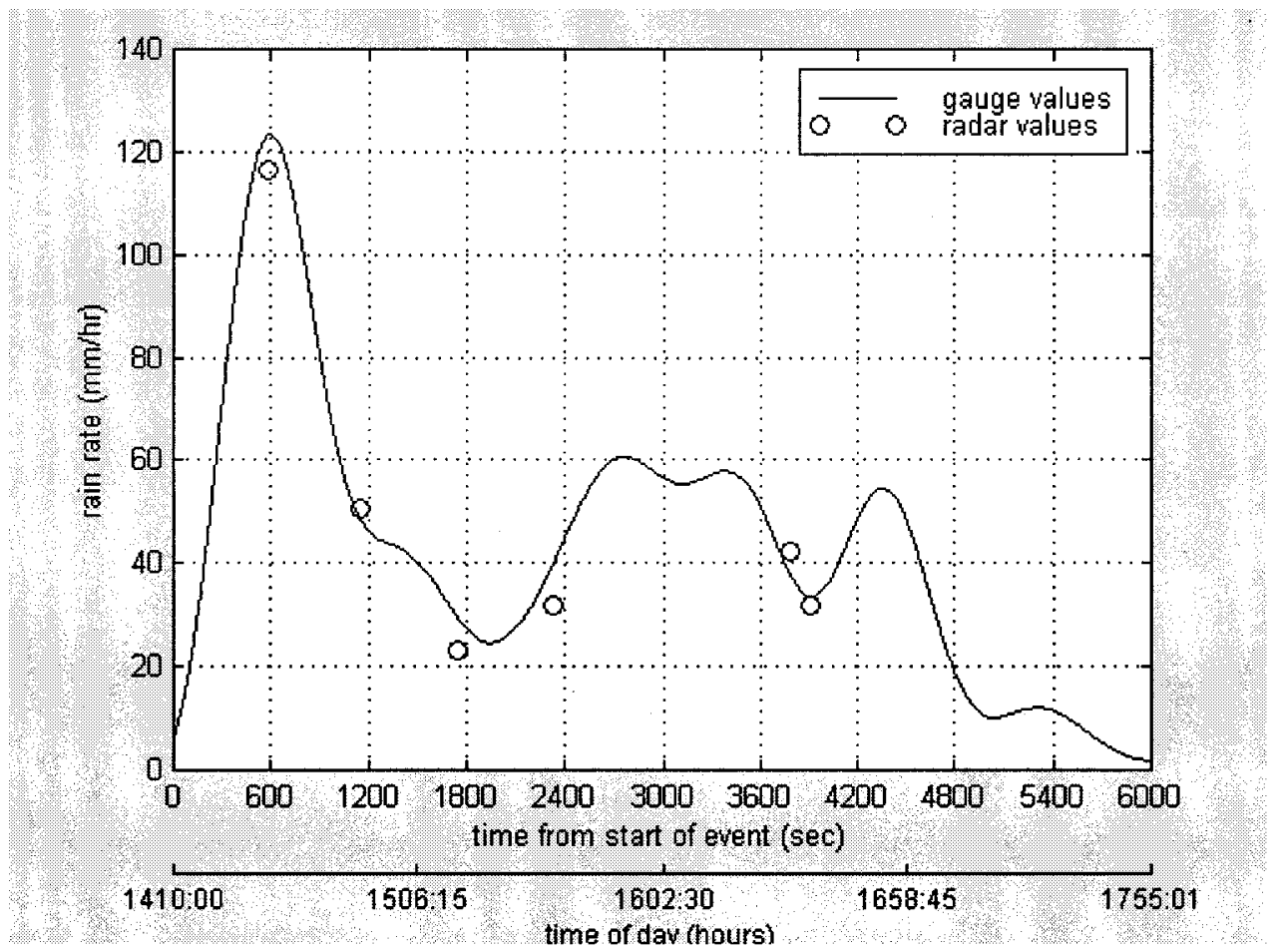

FIG. 9. (a) Time series of $Z_{h}$ (top panel), $Z_{\mathrm{DR}}$ (middle panel), and $K_{\mathrm{DP}}$ (bottom panel) after averaging over the optimal area. Open circles show the data points. Event is 20 June 1994, gauge 1. (b) Radar rain rate from $R\left(K_{\mathrm{DP}}\right)$ in Table 2 shown as open circles compared against the rain gauge (solid line). (c) Cumulative rainfall amounts from $R\left(K_{\mathrm{DP}}\right), R\left(K_{\mathrm{DP}}, Z_{\mathrm{DR}}, 1\right)$, and $R\left(Z_{h}, 53\right)$ compared with the gauge amounts over time. 
(c)

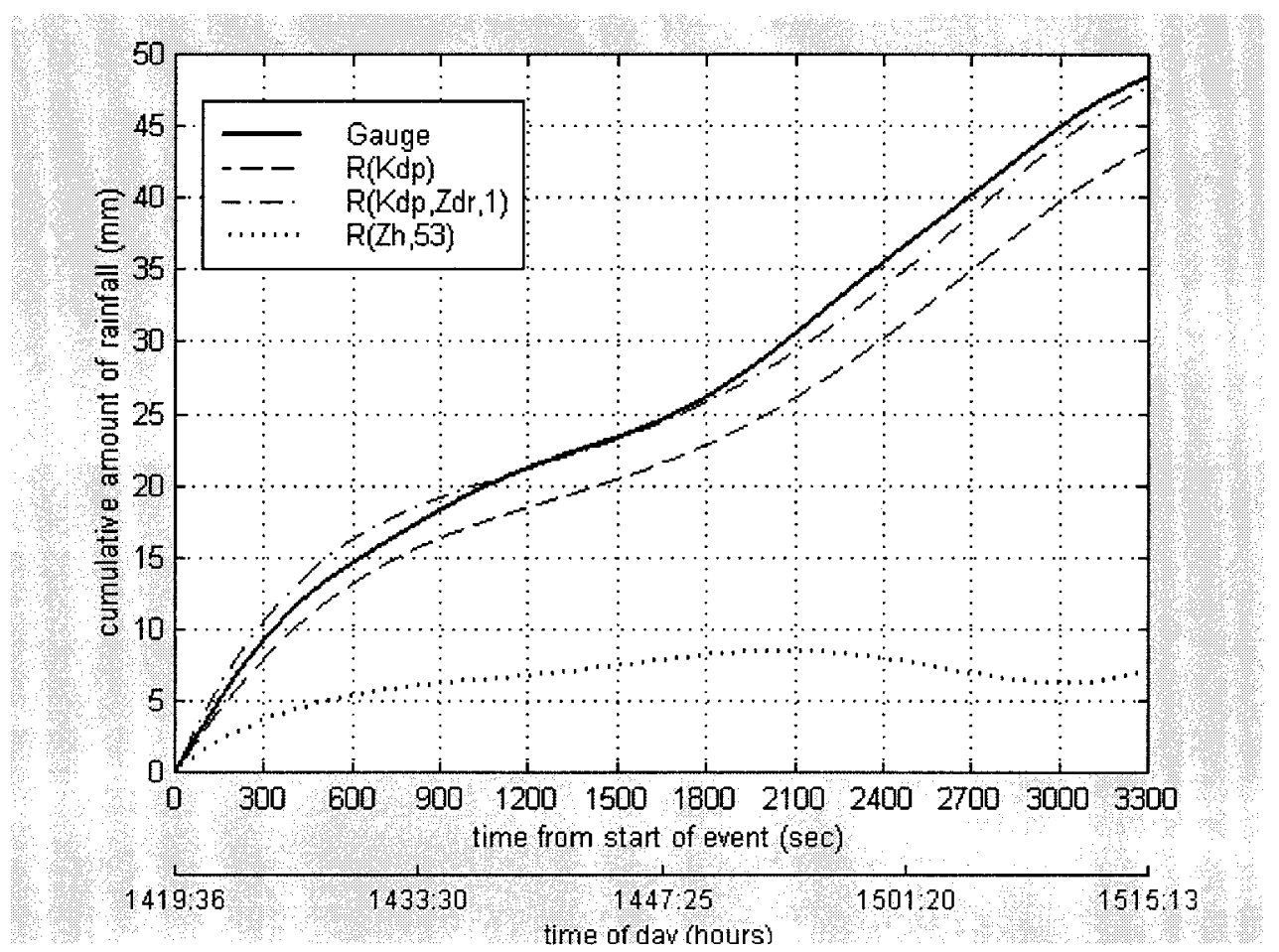

FIG. 9. (Continued)

\section{b. 2 June 1995}

On this day a mobile chase van with the Young gauge was directed from the radar to intercept a multicellular storm that produced intense rain rates over the van location. Observers in the van reported very tiny, peasized hail mixed with rain at times. Figure 2 shows contours of (a) $Z_{h}$ and (b) $K_{\mathrm{DP}}$ at an elevation angle of $1.0^{\circ}$ during the central time of the event (1812 MDT). Again, plots (a) and (b) are constructed similarly to those in Fig. 1. The gauge location is marked. PPI scans at this elevation angle were available at intervals of approximately $90 \mathrm{~s}$. The reflectivity structure in Fig. 2a is multicellular. The $K_{\mathrm{DP}}$ structure in Fig. 2b shows two cells; around the gauge location $K_{\mathrm{DP}}$ exceeds $3.5^{\circ} \mathrm{km}^{-1}$.

TABLE 4. Radar algorithms of rain rate $\left(\mathrm{mm} \mathrm{h}^{-1}\right)$ and fractional standard error (\%). Note: Algorithms are as defined in Table 2. Dash indicates entry is the same as the above previous value.

\begin{tabular}{lcccc}
\hline \hline & $\begin{array}{c}\text { 20 June } \\
1994 \\
\text { Algorithm }\end{array}$ & $\begin{array}{c}\text { 20 June } \\
\text { (Gauge 1) } \\
\text { (Gauge 2) }\end{array}$ & $\begin{array}{c}\text { 2 June } \\
1995\end{array}$ & $\begin{array}{c}\text { 6 July } \\
1996\end{array}$ \\
\hline$R\left(K_{\mathrm{DP}}\right)$ & 7.6 & 12.6 & 10.5 & 7.2 \\
$R\left(K_{\mathrm{DP}}, Z_{\mathrm{DR}}, 1\right)$ & 35.9 & 19.1 & 12.4 & 15.8 \\
$R\left(K_{\mathrm{DP}}, Z_{\mathrm{DR}}, 2\right)$ & 31.9 & 26.0 & 19.9 & 25.9 \\
$R\left(Z_{h}\right)$ & 58.9 & 37.3 & 35.6 & 53.4 \\
$R\left(Z_{h}, 55\right)$ & - & - & - & 36.3 \\
$R\left(Z_{h}, 53\right)$ & - & - & 37.2 & 14.2 \\
$R\left(Z_{h}, 51\right)$ & - & - & 39.4 & 30.7 \\
\hline
\end{tabular}

c. 6 July 1996

The mobile chase van was directed for a storm intercept on this day. Observers reported intense rain rates mixed with hail up to $1.7-\mathrm{cm}$ diameter. Figure 3 a shows the low elevation angle PPI scan of reflectivity at 1929 MDT. The gauge location is marked. In Fig. 3b several high $K_{\mathrm{DP}}$ cells are noted with the cell centered at $(-16$, $-15 \mathrm{~km}$ ), where $K_{\mathrm{DP}}$ is greater than $5^{\circ} \mathrm{km}^{-1}$.

\section{Optimal area method}

Radar data such as $Z_{h}, Z_{\mathrm{DR}}$, and $K_{\mathrm{DP}}$ are available in polar coordinates for each PPI scan. At each polar grid point, time series of radar parameters and rain rates based on $R\left(K_{\mathrm{DP}}\right), R\left(K_{\mathrm{DP}}, Z_{\mathrm{DR}}\right)$, and $R\left(Z_{h}\right)$ are generated (see Table 2) using consecutive PPI scans at the same elevation angle. These time series samples are spaced approximately $90 \mathrm{~s}$ apart for the 2 June 1995 event, approximately $560 \mathrm{~s}$ for the 20 June 1994 event, and approximately $50 \mathrm{~s}$ for the 6 July 1996 event.

The rain gauge accumulation data were sampled every few seconds for the 2 June 1995 and 6 July 1996 events and every $5 \mathrm{~min}$ for the gauge 1 event of 20 June 1994 event. Data from gauge 2 was available on a strip chart recorder and rain-rate estimates were based on 5min accumulations. To match the radar and gauge sampling intervals, the gauge data were passed through a 
(a)

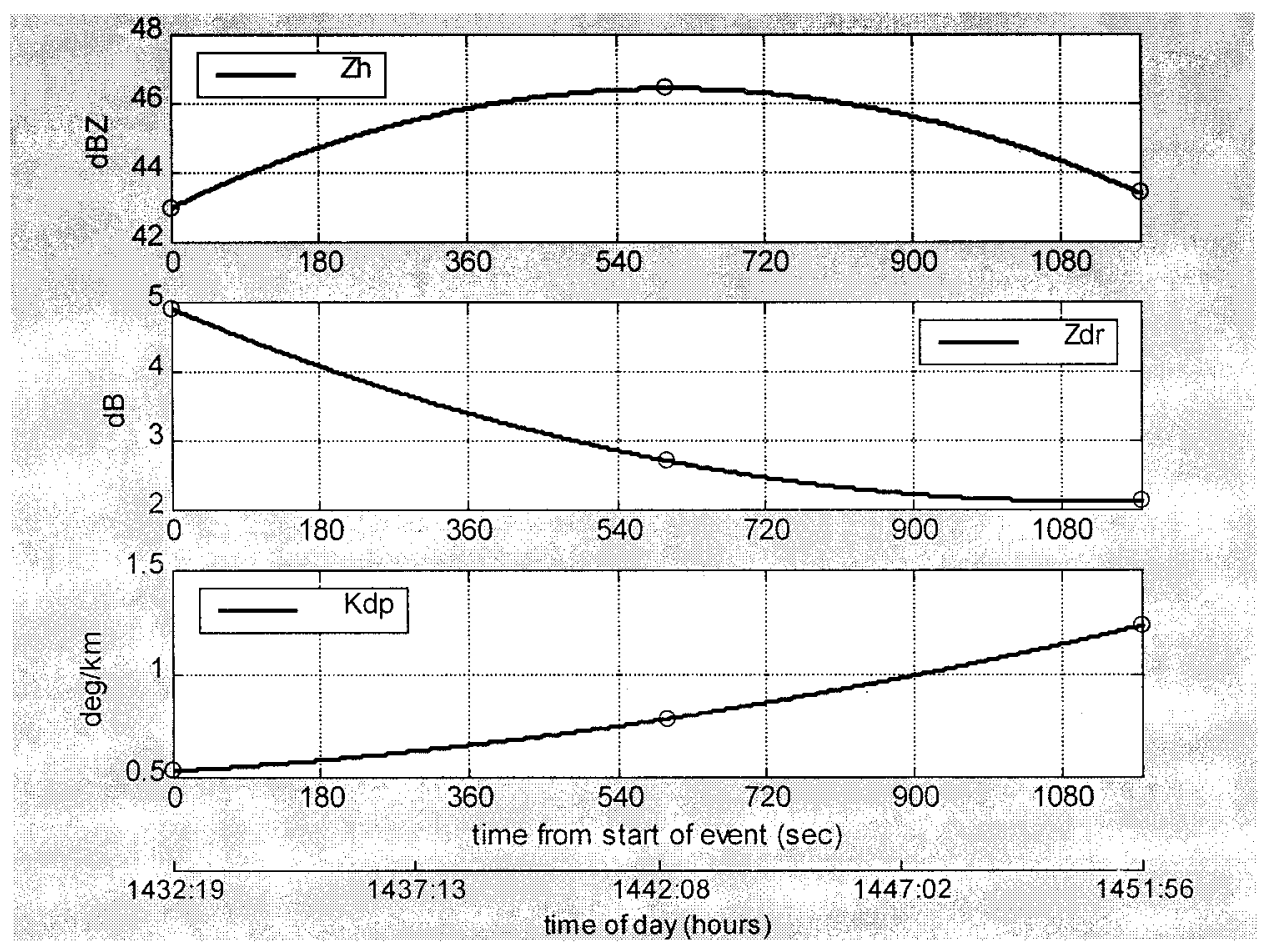

(b)

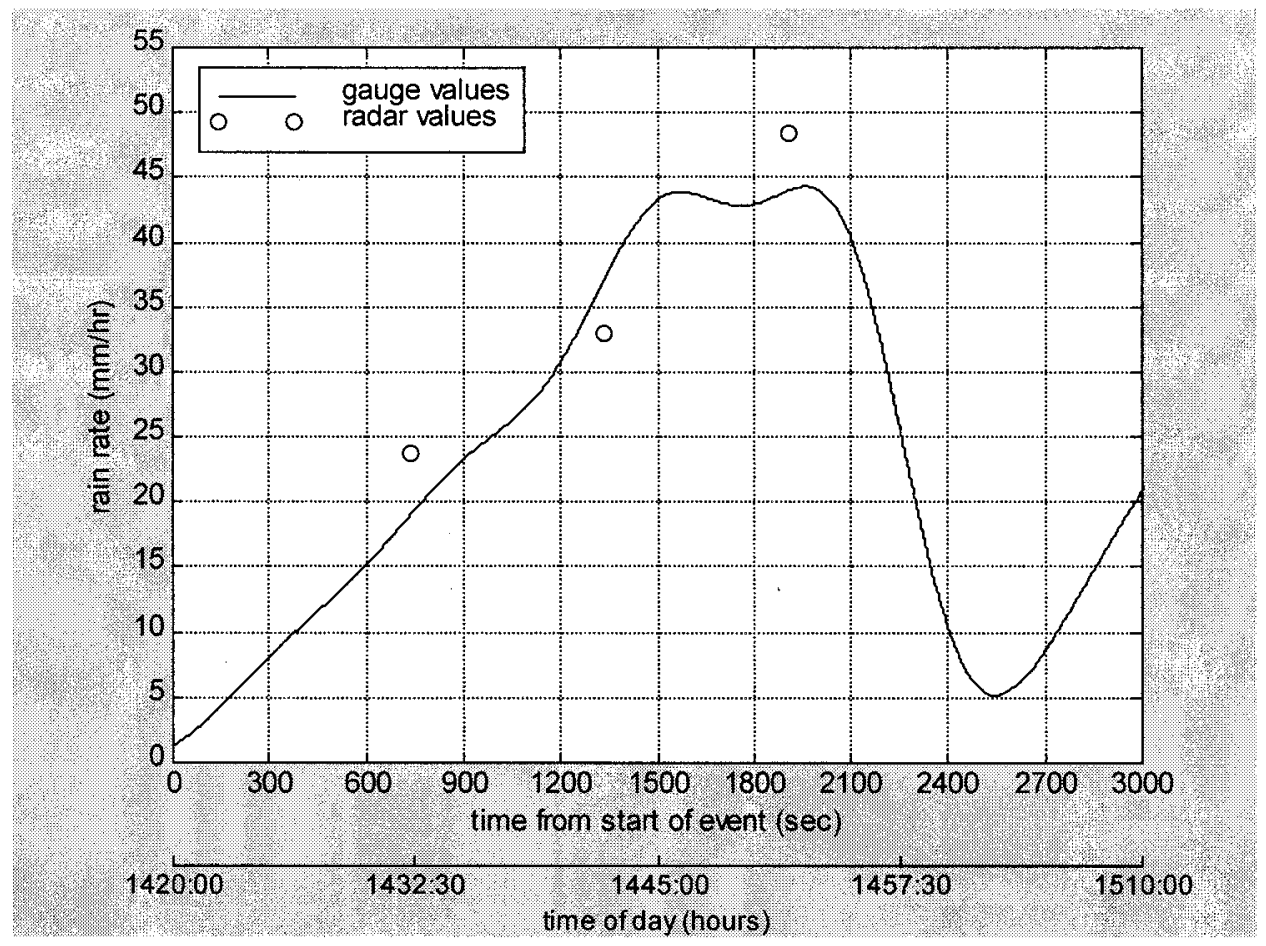

FIG. 10. (a) Time series of $Z_{h}$ (top panel), $Z_{\mathrm{DR}}$ (middle panel), and $K_{\mathrm{DP}}$ (bottom panel) after averaging over the optimal area. Open circles show the data points. Event is 20 June 1994, gauge 2. (b) Radar rain rate from $R\left(K_{\mathrm{DP}}\right)$ in Table 2 shown as open circles compared against the rain gauge (solid line). (c) Cumulative rainfall amounts from $R\left(K_{\mathrm{DP}}\right), R\left(K_{\mathrm{DP}}, Z_{\mathrm{DR}}, 1\right)$, and $R\left(Z_{h}, 53\right)$ compared with the gauge amounts over time. 
(c)

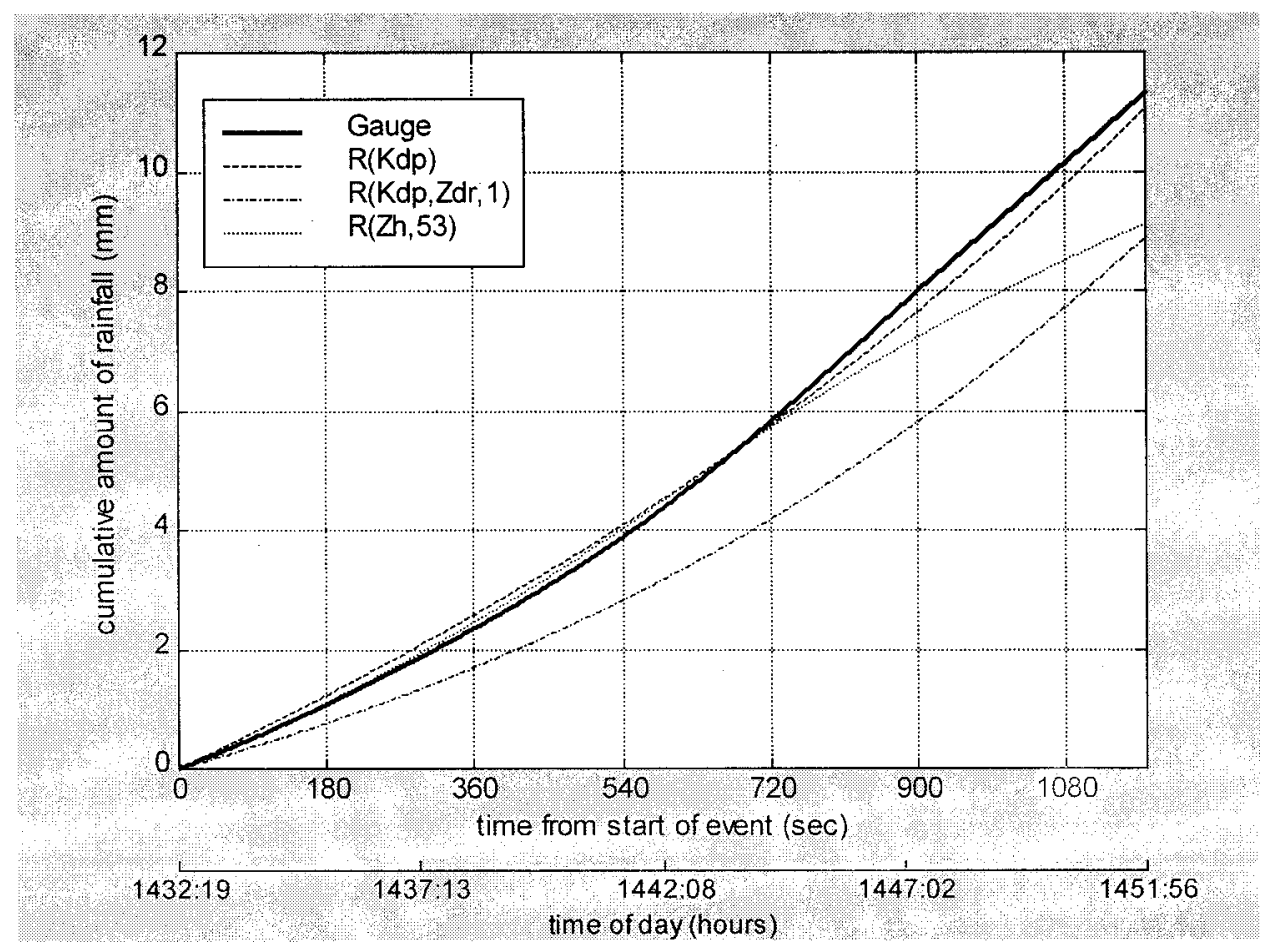

FIG. 10. (Continued)

low-pass filter with cutoff frequency adjusted to match the radar sampling rate for each event.

Data from the 2 June event are used in this section to describe the development of the optimal area method. An important consideration in the development of the optimal area is the temporal and spatial variability of rainfall. The location and spatial dimension of the optimal area is assumed to change with time. We use the gauge measurement to provide insight into choosing a statistically significant time window over which the comparison can be made. The length of time that an area is matched to the gauge report is determined by estimating the autocorrelation of the gauge rain rate over the entire rain event. A smooth, decaying exponential is best fit to the autocorrelation estimate. The time $\tau_{g}$, where the value of the best-fit curve is equal to $1 / e$, is chosen as the window size for the event. The time series of the radar rain-rate estimate is cropped to a window size that is $\tau_{g}$ in length. The shortened time series are then used for comparison against the rain gauge data.

Radar data are shifted in time across the gauge data. The rms difference $\left(\mathrm{mm} \mathrm{h}^{-1}\right)$ between the two measures is calculated at successive time increments. The minimum radar-gauge rms value is then found from all of the time lag calculations:

$\mathrm{rms}=\min \left\{\frac{1}{n} \sum_{i=1}^{n}\left[R_{\mathrm{ri}}(t+\tau)-R_{\mathrm{gi}}(t)\right]^{2}\right\}^{1 / 2} \mathrm{~mm} \mathrm{~h}^{-1}$, where $R_{\mathrm{ri}}$ and $R_{\mathrm{gi}}$ are the radar-estimated and gaugemeasured rain rates, respectively. Figure $4 \mathrm{a}$ shows $R\left(K_{\mathrm{DP}}\right)$ from Table 2 versus time through a point located southeast of the gauge. Gauge time is considered as the absolute frame of reference. Figure $4 \mathrm{~b}$ shows the filtered gauge rain-rate data. Radar time samples are paired to a corresponding gauge value, and the rms difference between the two series is calculated. The radar time series is shifted ahead sequentially over the interval 0 $\leq \tau \leq \tau_{g} / 2$. This procedure is repeated for all of the radar time series that were previously constructed through each grid point. For this example, the best radar-gauge match is obtained when the radar data is slid $103 \mathrm{~s}$ ahead in time, demonstrating a forward delay between the radar measurement and the gauge measurement. When all of the radar-gauge matches are completed, resulting in contours of radar-gauge rms difference $\left(\mathrm{mm} \mathrm{h}^{-1}\right)$ for all of the points in the grid, the minimum rms value is found from all possible point locations. The polar grid point that contains the time series that has the smallest rms difference is chosen as the center location of the optimal area. The time lag associated with this point is used as the initial optimal time lag $\tau_{\text {opt }}$ for this radar set. Now, $\tau$ in Eq. (1) is set to $\tau_{\text {opt }}$ and the rms difference for each radar-gauge comparison is recomputed. The result is shown in Fig. 5a; areas of minimum rms difference centered near (14, $-10 \mathrm{~km})$ are accentuated, while large rms difference 
(a)

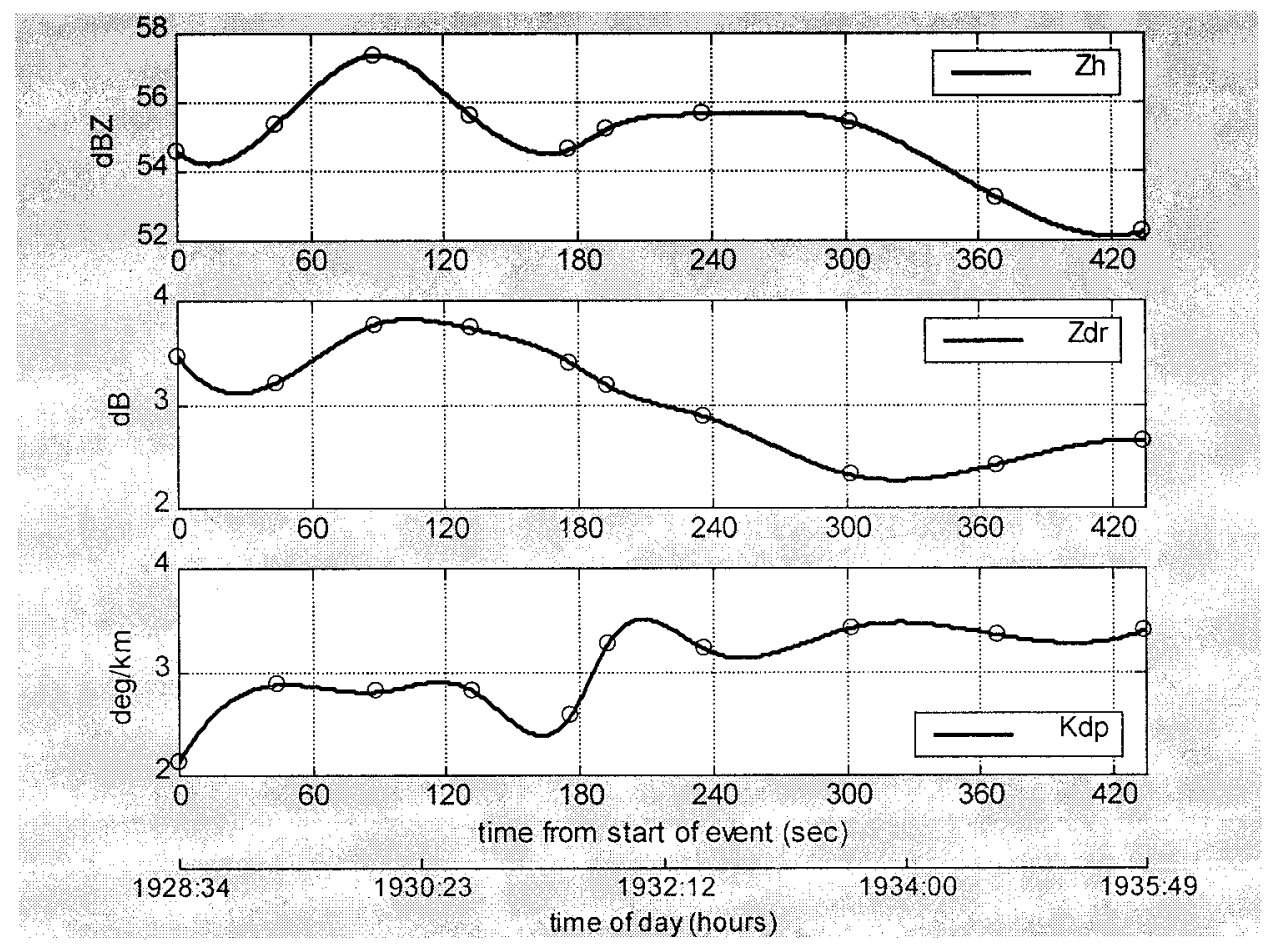

(b)

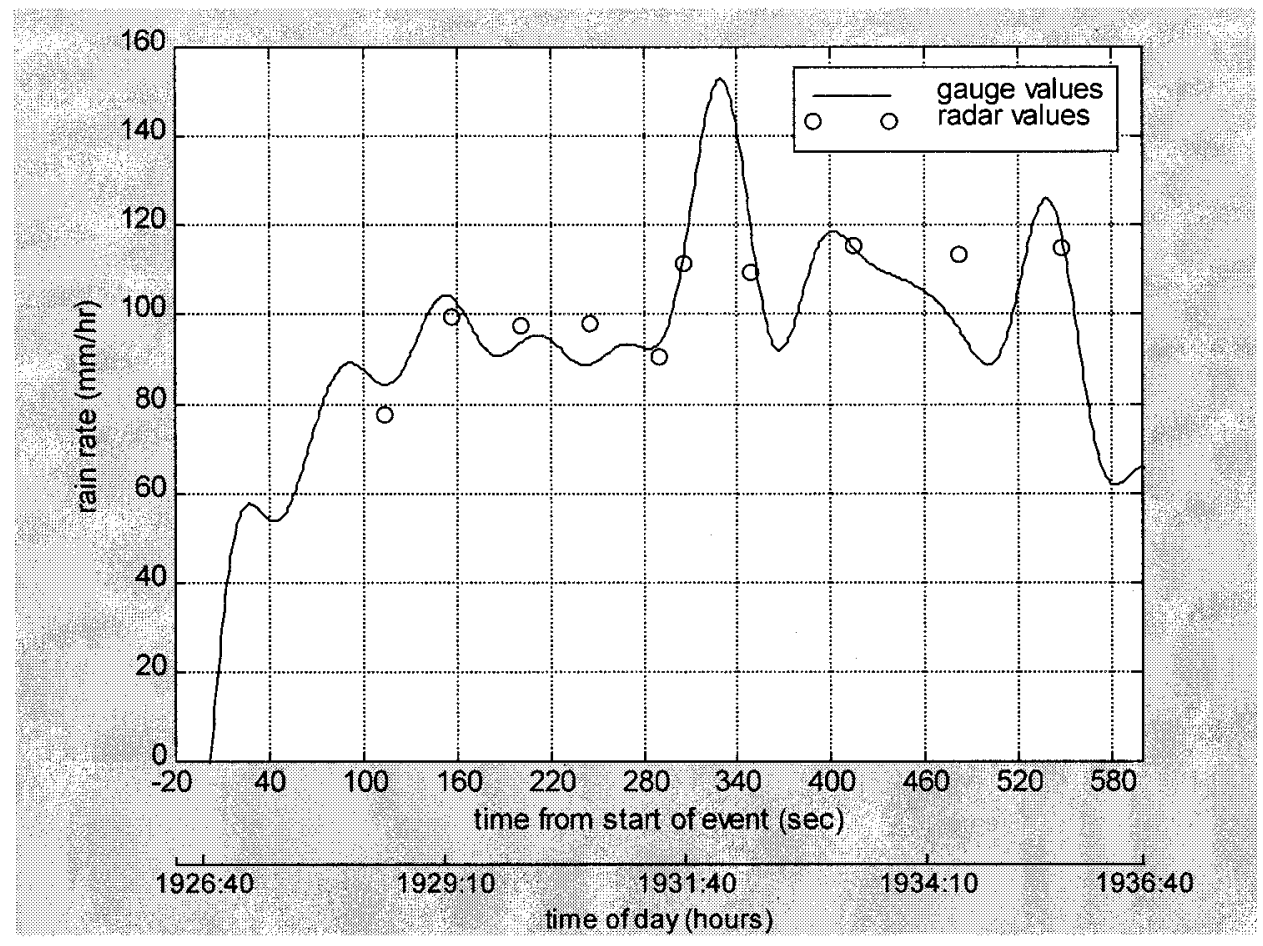

FIG. 11. (a) Time series of $Z_{h}$ (top panel), $Z_{\mathrm{DR}}$ (middle panel), and $K_{\mathrm{DP}}$ (bottom panel) after averaging over the optimal area. Open circles show the data points. Event is 6 July 1996. (b) Radar rain rate from $R\left(K_{\mathrm{DP}}\right)$ in Table 2 shown as open circles compared against the rain gauge (solid line). (c) Cumulative rainfall amounts from $R\left(K_{\mathrm{DP}}\right), R\left(K_{\mathrm{DP}}, Z_{\mathrm{DR}}, 1\right)$, and $R\left(Z_{h}, 53\right)$ compared with the gauge amounts over time. 
(c)

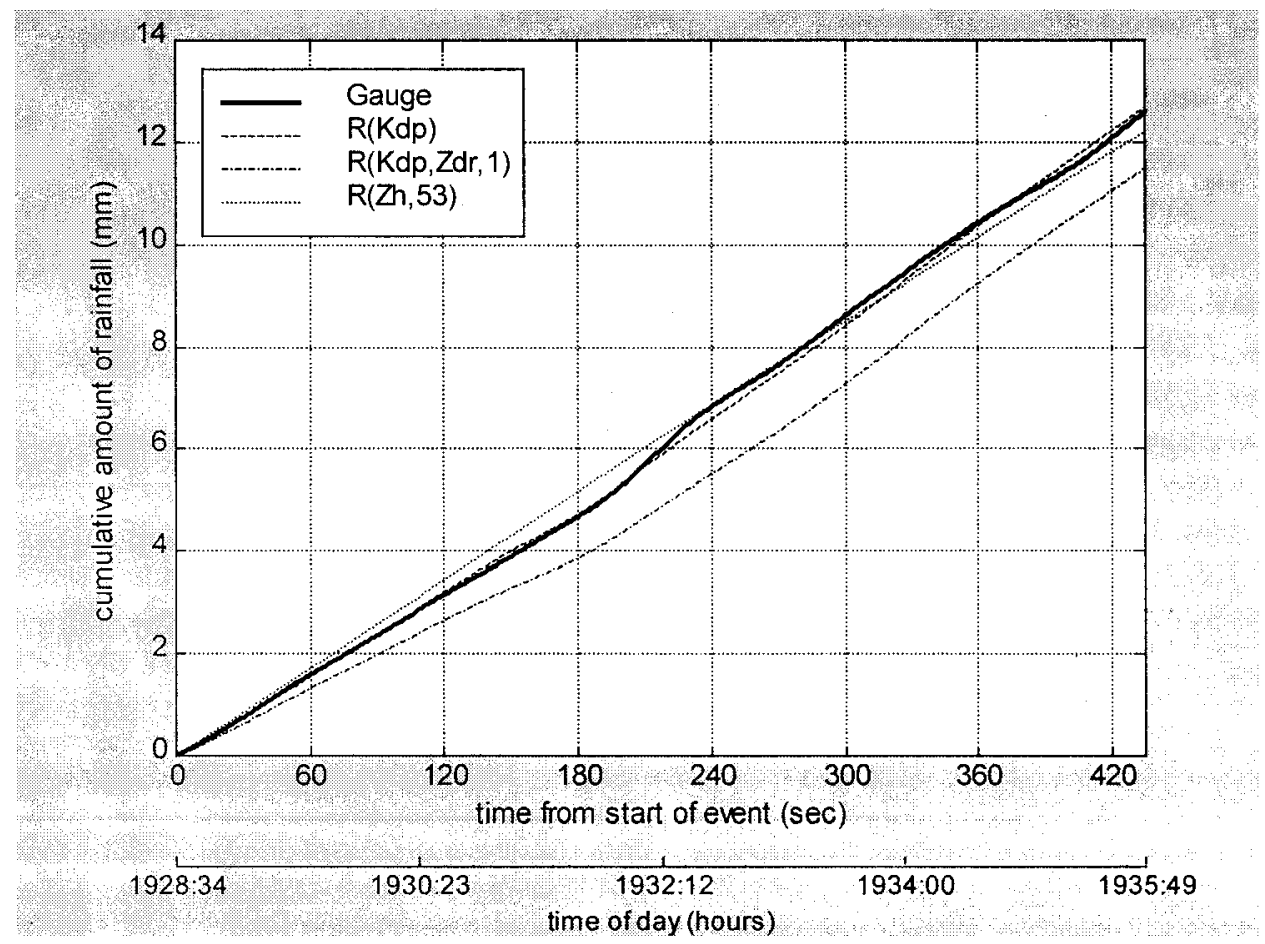

FIG. 11. (Continued)

areas are deemphasized, providing a clear resolution of the candidate optimal areas. Figure $5 \mathrm{~b}$ shows contours of the rms difference field when the $R\left(Z_{h}, 53\right)$ algorithm from Table 2 is used. It is clear that a well-defined areal minimum cannot be located. Part of the reason why the $R\left(K_{\mathrm{DP}}\right)$ algorithm yields a well-defined areal minimum (see Fig. 5a) is that it has a closer relationship to the true rain rate. However, $K_{\mathrm{DP}}$ is derived from filtered range profiles of $\Phi_{\mathrm{DP}}$. On the other hand, the $R\left(Z_{h}, 53\right)$ algorithm uses "raw" reflectivity values. If $Z_{h}$ is filtered along range to the same extent as $\Phi_{\mathrm{DP}}$, a long and skinny areal minimum is obtained that is aligned along the radial to the radar. The areal minimum in Fig. 5a is not long and skinny, although it is aligned along the radial to the radar (in this case). Thus, while radial smoothing of the $\Phi_{\mathrm{DP}}$ data is conducive to the generation of a welldefined areal minimum for the rms error field, we believe that the closer physical relationship between $K_{\mathrm{DP}}$ and rain rate also plays a role.

The geometry of the optimal area is taken to be elliptical to provide sufficient flexibility in the construction of the optimal area. One axis of the ellipse is directed along a line running from the gauge location to the candidate point location referred to as the "gaugepoint axis line." The cross-axis line is orthogonal to the gauge-point line. The two lines cross at the center of the ellipse, which is coincident with the minimum point location that was previously found. An example is shown in Fig. 6a that shows a candidate optimal area center point location relative to the gauge location. Figure $6 \mathrm{~b}$ shows the rms error along the gauge-point and cross-axis lines. The next task is to use the rms error structure to define the dimensions of the optimal area. Rather than using an arbitrary cutoff level of the error measure, an adaptive procedure is used. The ellipse dimensions of the optimal area are estimated from the decorrelation distances of the rms error along the gaugeaxis and cross-axis lines, as illustrated in Fig. 6c. Figure 7 shows the location of the gauge and the elliptical optimal area. In this case the major axis is $0.92 \mathrm{~km}$ and the minor axis is $0.88 \mathrm{~km}$ (see also Table 3 ). To avoid arbitrarily small optimal areas that can occur in the error minimization procedure, the equivalent circular diameter must be at least as large as the radar beamwidth. The mean value of the radar parameters $Z_{h}, Z_{\mathrm{DR}}$, and $K_{\mathrm{DP}}$ are then determined within the elliptical area. These new values are then used to recalculate the radar-estimated rain rate using the algorithms in Table 2 that are then compared to the gauge measurements.

Several comments on the method are relevant here. For the four events analyzed, the optimal ellipse's axis ratio is typically $0.8-0.9$ (see Table 3 ); that is, they are not long and skinny. In addition, the angle between the ellipse's major axis and the radial to the radar is given in Table 3, and for two of the events (20 June gauge 2 and 6 July 1996) this angle is around $30^{\circ}-60^{\circ}$. Thus, the ellipse is not always aligned along the radial. These properties of the optimal ellipse suggest that radial 
smoothing of the $\Phi_{\mathrm{DP}}$ data (which is necessary for accurate $K_{\mathrm{DP}}$ determination) is not the only reason why a well-defined areal minimum in the rms difference field occurs While it is possible to use Eq. (1) with $Z-R$ relations (e.g., see Fig. 5b), and thereby arrive at an optimal ellipse, the location of the ellipse could be in error since $Z-R$ relations are generally biased. We also note here that this methodology is appropriate only when unbiased rain-rate algorithms are used.

\section{Results and discussion}

In all the four events described below the $R\left(K_{\mathrm{DP}}\right)$ algorithm (see Table 2) is used to derive the optimal area.

\section{a. 2 June 1995 event}

As mentioned in section 3, this event was dominated by heavy rainfall with practically no hail mixed in. Table 3 lists the parameters of the elliptical optimal area, the optimum time shift, and the height of the radar measurements above ground. The location of the optimal area is consistent with observed rain cell movement from the southeast direction. The area over which the radar measurements are averaged is generally consistent with the optimal area analysis of Aydin et al. (1987).

Figure 8a shows the radar parameters $Z_{h}, Z_{\mathrm{DR}}$, and $K_{\mathrm{DP}}$ averaged over the optimal area versus time. Note the coincidence of peak $Z_{h}$ of $54 \mathrm{dBZ}$ and peak $K_{\mathrm{DP}}$ of $3.5^{\circ} \mathrm{km}^{-1}$ at $240 \mathrm{~s}$. Toward the end of the event, a region of $Z_{h} \approx 50 \mathrm{dBZ}, Z_{\mathrm{DR}} \approx 4 \mathrm{~dB}$, and lower $K_{\mathrm{DP}} \approx 2^{\circ} \mathrm{km}^{-1}$ indicative of lower rain rates but with a larger preponderance of bigger-sized drops can be noted. Figure $8 b$ shows the gauge rain-rate profile for the entire event (solid line) compared with $R\left(K_{\mathrm{DP}}\right)$ from the radar (open circles). Note the excellent agreement between the two rain-rate profiles. Figure $8 \mathrm{c}$ compares the time cumulative rainfall profile obtained from the various rainfall algorithms with gauge data. It is clear that the $K_{\mathrm{DP}}$-based algorithms follow the gauge profile very well compared to $R\left(Z_{h}, 53\right)$. The fractional standard error (FSE) in rain rate is defined as

$$
\mathrm{FSE}=\frac{\left\{\left\langle\left(R_{i}-G_{i}\right)^{2}\right\rangle\right\}^{1 / 2}}{\left\langle G_{i}\right\rangle},
$$

where $G_{i}$ is the gauge rain rate, $R_{i}$ is the corresponding rain rate from the radar-based algorithms, and angle brackets $(\langle\rangle)$ indicate sample averaging. Table 4 lists the FSE values of the various algorithms. The FSE values for the $K_{\mathrm{DP}}$-based algorithms are in the range obtained from theoretically based simulations of gamma DSD and measurement errors (Chandrasekar et al. 1990; Ryzhkov and Zrnic 1995). For example, the simulations of Ryzhkov and Zrnic (1995) showed that the FSE using $K_{\mathrm{DP}}$-based algorithms can be in the range 5\%-20\% in agreement with the results in Table 4. The $Z_{h}$-based algorithms in Table 4 give an FSE around 35\%-40\% in good agreement with simulations (Chandrasekar and Bringi 1988) and observations of Aydin et al. (1990).

\section{b. 20 June 1994 event: Gauge 1}

As mentioned in section 3, this event was characterized by marble-sized hail mixed with rain. The PPI scans performed on the 20 June storm were not optimal for radar-gauge comparisons using the optimal area method. For example, the $0.5^{\circ}$ elevation angle sweep was repeated with interval of approximately $500 \mathrm{~s}$. The tipping-bucket gauge recorded rainfall amounts only every 5 min from which rain rate was calculated. Table 3 lists the characteristics of the optimal area for this event. Figure 9a shows the radar measurements averaged over the optimal area. Figure $9 \mathrm{~b}$ compares $R\left(K_{\mathrm{DP}}\right)$ with gauge rates and excellent agreement is noted. Figure 9c compares the cumulative rainfall amounts from the various algorithms, and again good agreement is noted except for $R\left(Z_{h}, 53\right)$, which underestimates by $80 \%$. Table 4 lists the FSE values for this case. Because the $Z_{h}$ values averaged over the optimal area are less than $51 \mathrm{dBZ}$, no change in FSE is seen for the various truncation levels. It is not clear why the FSEs are so large for $R\left(K_{\mathrm{DP}}, Z_{\mathrm{DR}}\right)$ algorithms; perhaps it is related to marblesized hail. However, they introduce very low bias (less than $8 \%$ ).

\section{c. 20 June 1994 event: Gauge 2}

There was no hail contamination during this event based on visual observations. Table 3 lists the characteristics of the optimal ellipse. Figure 10a shows the averaged radar data, and the poor radar time sampling is clearly evident since only three data points are available within the time window. Figure 10b compares the rain rate, while Fig. 10c compares the rain accumulation The FSE values in Table 4 for this event are in the range $10 \%-25 \%$ for the $K_{\mathrm{DP}}$-based algorithms, and around $40 \%$ for the $Z-R$, again, in agreement with theoretical results.

\section{d. 6 July 1996 event}

This event was characterized by marble-sized hail (up to $1.7-\mathrm{cm}$ diameter) mixed with intense rain. Table 3 lists the optimal ellipse parameters. Figure 11a shows the averaged radar data, while Fig. $11 \mathrm{~b}$ compares rain rates showing excellent agreement. Table 4 lists the FSE values that are in general agreement with theoretical simulations, while Fig. 11c shows the cumulative rainfall amounts. In this case, the $R\left(Z_{h}, 53\right)$ algorithm produced low FSE (14\%) and negligible bias.

\section{Conclusions}

An optimal area method is described that is used as a basis for comparing radar-based rain-rate estimators 
with gauge rain rates. The location and dimensions of an elliptically shaped optimal area within the radar PPI scan are determined objectively via an rms error minimization procedure between the radar-based rain-rate estimator, $R\left(K_{\mathrm{DP}}\right)$, and gauge-measured rain rate, and via using the spatial structure of the rms error field. This structure revealed a well-defined areal minimum partly because of a close physical relationship between $K_{\mathrm{DP}}$ and rain rate. Though, in principle, any rainfall algorithm can be used in the error minimization procedure, this does not guarantee a "meaningful" optimal area unless the algorithm is unbiased.

The optimal area-averaged rain rates using $K_{\mathrm{DP}^{-}}$and $Z_{h}$-based estimators were compared with the gauge rain rate, and fractional standard errors were determined. The cumulative rainfall amounts were also compared. The fractional standard errors obtained when using $R\left(K_{\mathrm{DP}}\right)$ or $R\left(K_{\mathrm{DP}}, Z_{\mathrm{DR}}\right)$ were generally in agreement with theoretically predicted simulation results (Ryzhkov and Zrnic 1995). Our results further support the conclusions of Ryzhkov and Zrnic (1995) and Aydin et al. (1995) that $K_{\mathrm{DP}}$-based rain-rate estimators offer an excellent, physically based radar method of measuring rain rates in precipitation contaminated or uncontaminated by hail.

Acknowledgments. VNB and VC acknowledge support from the AFOSR via Grant F49620-95-1-0133. The instrumented chase van was funded by the Center for Geosciences Phase II at CSU via DOD Grant DAAH0494-G-0420. SB acknowledges support from USAF/ Rome Laboratory. The authors acknowledge the assistance of Dr. John Hubbert of CSU in collecting the van data.

\section{REFERENCES}

Austin, P., 1987: Relation between measured radar reflectivity and surface rainfall. Mon Wea Rev, 115, 1053-1071.

Aydin, K., H. Direskeneli, and T. A. Seliga, 1987: Dual polarization radar estimation of rainfall parameters compared with groundbased disdrometer measurements: 29 October 1982 central Il- linois experiment. IEEE Trans. Geosci. Remote Sens., 25, 834844.

— - Y.-M. Lure, and T. A. Seliga, 1990: Polarimetric radar measurements of rainfall compared with ground-based rain gauges during Maypole '84. IEEE Trans. Geosci. Remote Sens., 28, 443-449.

- V. N. Bringi, and L. Liu, 1995: Rain-rate estimation in the presence of hail using S-band, specific differential phase and other radar parameters. J. Appl. Meteor., 34, 404-410.

Chandrasekar, V., and V. N. Bringi, 1988: Error structure of multiparameter radar and surface measurements of rainfall. Part I: Differential reflectivity. J. Atmos. Oceanic Technol., 5, 783-795.

— , V., V. N. Bringi, N. Balakrishnan, and D. S. Zrnic, 1990: Error structure of multiparameter radar and surface measurements of rainfall. Part III: Specific differential phase. J. Atmos. Oceanic Technol., 7, 621-629.

Doviak, R. J., and D. S. Zrnic, 1993: Doppler Radar and Weather Observations. 2d ed. Academic Press, 562 pp.

Goddard, J. W. F., and S. M. Cherry, 1984: The ability of dualpolarization radar (copolar linear) to predict rainfall rate and microwave attenuation. Radio Sci., 19, 201-208.

Gorgucci, E., and G. Scarchilli, 1994: A robust estimator of rainfall using differential reflectivity. J. Atmos. Oceanic Technol., 11, 586-592.

_ , V. Chandrasekar, and G. Scarchilli, 1995: Radar and surface measurement of rainfall during CaPE: 26 July 1991 case study. J. Appl. Meteor., 34, 1570-1577.

Hubbert, J., and V. N. Bringi, 1995: An iterative filtering technique for the analysis of copolar differential phase and dual-frequency radar measurements. J. Atmos. Oceanic Technol., 12, 634-648.

Kelsh, M., 1989: An evaluation of the NEXRAD hydrology sequence for different types of convective storms in northeastern Colorado. Preprints, 24th Conf. on Radar Meterology, Tallahassee, FL, Amer. Meteor. Soc., 207-210.

Mueller, E. A., 1984: Calculation procedures for differential propagation phase shift. Preprints, 22d Conf. on Radar Meteorology, Zurich, Switzerland, Amer. Meteor. Soc., 397-399.

Nystuen, J. A., J. R. Proni, P. G. Black, and J. C. Wilkerson, 1996: A comparison of automatic rain gauges. J. Atmos. Oceanic Technol., 13, 62-73.

Ryzhkov, A. V., and D. S. Zrnic, 1995: Comparison of dual-polarization radar estimators of rain. J. Atmos. Oceanic Technol., 12, 249-256.

Zawadzki, I., 1975: On radar-rain gage comparison. J. Appl. Meteor., 14, 1430-1436.

— 1984: Factors affecting the precision of radar measurements of rain. Preprints, 22d Conf. on Radar Meteorology, Zurich, Switzerland, Amer. Meteor. Soc., 251-256.

Zrnic, D. S., and A. Ryzhkov, 1996: Advantages of rain measurements using specific differential phase. J. Atmos. Oceanic Technol., 13, 454-464. 